Review

\title{
RNAi in Arthropods: Insight into the Machinery and Applications for Understanding the Pathogen-Vector Interface
}

\author{
Annette-Christi Barnard ${ }^{1}$, Ard M. Nijhof ${ }^{2}$, Wilma Fick ${ }^{3}$, Christian Stutzer $^{1}$ and \\ Christine Maritz-Olivier ${ }^{3, *}$ \\ 1 Department of Biochemistry, University of Pretoria, Pretoria, 0002, South Africa; \\ E-Mails: annettechristi@gmail.com (A.C.B.); christian.stutzer@gmail.com (C.S.) \\ 2 Institut für Parasitologie und Tropenveterinärmedizin, Freie Universität Berlin, Königsweg 67, \\ 14163, Berlin, Germany; E-Mail: ardmenzo.nijhof@fu-berlin.de \\ 3 Department of Genetics, University of Pretoria, Pretoria, 0002, South Africa; \\ E-Mail: wilma.fick@up.ac.za
}

* Author to whom correspondence should be addressed; E-Mail: christine.maritz@up.ac.za; Tel.: +27-012-420-3945; Fax: +27-012-362-5327.

Received: 3 September 2012; in revised form: 19 October 2012 / Accepted: 23 October 2012 / Published: 6 November 2012

\begin{abstract}
The availability of genome sequencing data in combination with knowledge of expressed genes via transcriptome and proteome data has greatly advanced our understanding of arthropod vectors of disease. Not only have we gained insight into vector biology, but also into their respective vector-pathogen interactions. By combining the strengths of postgenomic databases and reverse genetic approaches such as RNAi, the numbers of available drug and vaccine targets, as well as number of transgenes for subsequent transgenic or paratransgenic approaches, have expanded. These are now paving the way for in-field control strategies of vectors and their pathogens. Basic scientific questions, such as understanding the basic components of the vector RNAi machinery, is vital, as this allows for the transfer of basic RNAi machinery components into RNAi-deficient vectors, thereby expanding the genetic toolbox of these RNAi-deficient vectors and pathogens. In this review, we focus on the current knowledge of arthropod vector RNAi machinery and the impact of RNAi on understanding vector biology and vector-pathogen interactions for which vector genomic data is available on VectorBase.
\end{abstract}

Keywords: RNA interference; vector; disease; mosquito; ixodid ticks; body louse; kissing bug; tsetse fly; transgenesis; vaccine; drug target 


\section{Introduction}

Vector-borne diseases are caused by pathogens that are transmitted between vertebrate hosts by another organism, predominantly via the saliva of blood-sucking arthropods, such as mosquitoes, fleas, lice, biting flies, mites and ticks. These may cause high incidences of morbidity, and in some instances mortality, not only affect low-income developing countries but also developed countries [1,2]. Biophysical, anthropogenic and climate changes affect vector population dynamics and disease transmission, as they influence the survival and reproduction rates of vectors. This in turn influences the distribution and abundance, habitat suitability, intensity and temporal pattern of vector activity throughout the year, and rates of development, survival and reproduction of pathogens within vectors [3]. As the severity of any vector-borne disease depends on the pathogen, the invertebrate vector and the human or animal host, understanding of the host-vector-pathogen interfaces is vital to gain insight into vector biology as well as pathogen survival and transmission.

In this post-genomic era, scientists aim to obtain an integrative view of the host-vector-pathogen interfaces using studies that comprise genomics, transcriptome and proteome analyses, population biology and vector biology. In combination, this will expedite the development of novel therapeutics and vaccination alternatives and is already a major focus in research on mosquitoes [4], trypanosomes [5], tick-borne pathogens [6,7] as well as species-specific insecticides [8]. In 2006, VectorBase, a NIAID-funded Bioinformatic Resource Center, focused on invertebrate vectors of disease, was established online [9]. To date, it houses the genomes of Anopheles gambiae (vector for malaria), Aedes aegypti (vector for yellow fever and dengue fever), Culex pipiens (vector for lymphatic filariasis and West Nile fever), the body louse Pediculus humanus (vector for epidemic typhus), the triatomine Rhodnius prolixus (vector for Chagas disease), the tsetse fly Glossina morsitans (vector for sleeping sickness) and the tick Ixodes scapularis (vector for Lyme disease) (http://www.vectorbase.org). The availability of these vectors' genomic resources, in combination with completed genome sequences of a number of their associated pathogens (Table 1), has necessitated the development of annotation/ontology tools to describe vector processes that are involved in vector survival and disease transmission. As a result, researchers are now faced with annotation of a large number of genes with unknown functions [10].

RNA interference, which refers to the silencing of the expression of a single gene, coupled with the resulting phenotype, has been used with great success in most of the abovementioned vectors for a growing understanding of function, as described in Section 2. The molecular mechanisms underlying the processes of dsRNA uptake, silencing, amplification and spreading of the silencing effect, as well as the proteins involved in these processes, however, remain to be clarified (Table 2). Based on RNAi methodology, the development of high-throughput genome-wide assay platforms for disease vectors is rapidly providing insight into host genes that are affected during pathogen infection. RNAi studies offers to facilitate gene annotation, unraveling the molecular interactions between vector-host and vector-pathogen and ultimately aiding in the discovery of novel vaccine and drug targets.

In this review, we bring together the current knowledge on the RNAi machinery and mechanisms in vectors housed on VectorBase. In the first part, we focus on the progress made in terms of expanding our knowledge on invertebrate RNAi machinery and processes, followed by examples were RNAi has expanded our knowledge of the host-vector-pathogen interfaces. Finally, we highlight the current 
status and future directions of RNAi and 'omics technology in controlling vectors and their associated pathogens.

Table 1. Summary of vectors addressed in this review with their respective diseases, hosts and genomic summaries. Adapted from [11,12].

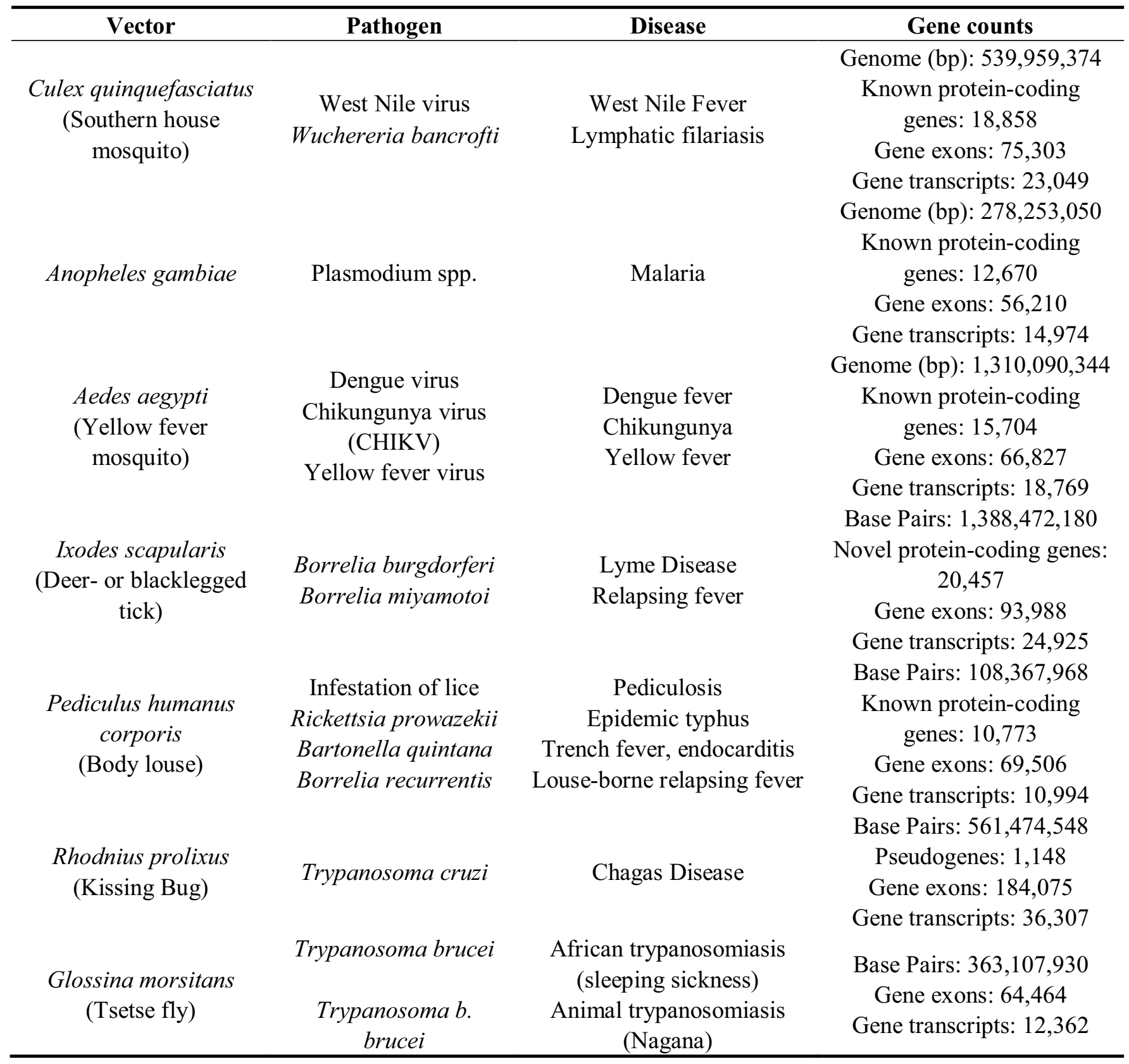

\section{Invertebrate RNAi Machinery}

RNAi can be broadly defined as a class of processes that use short RNAs to regulate transcriptional and post-transcriptional gene regulation. Since the discovery of RNAi, numerous in vivo and in vitro studies have been performed to improve our understanding of the RNAi processes, and to identify the different components of the RNAi machinery of disease-causing organisms. From a combination of results, a widely conserved three step mechanistic model for RNAi has been derived (Figure 1) [13,14]. 
Table 2. Small RNA species and RNAi machinery described in vectors of disease and their associated transmitted pathogens. The human louse is not included as there is no current information on RNAi machinery in this organism.

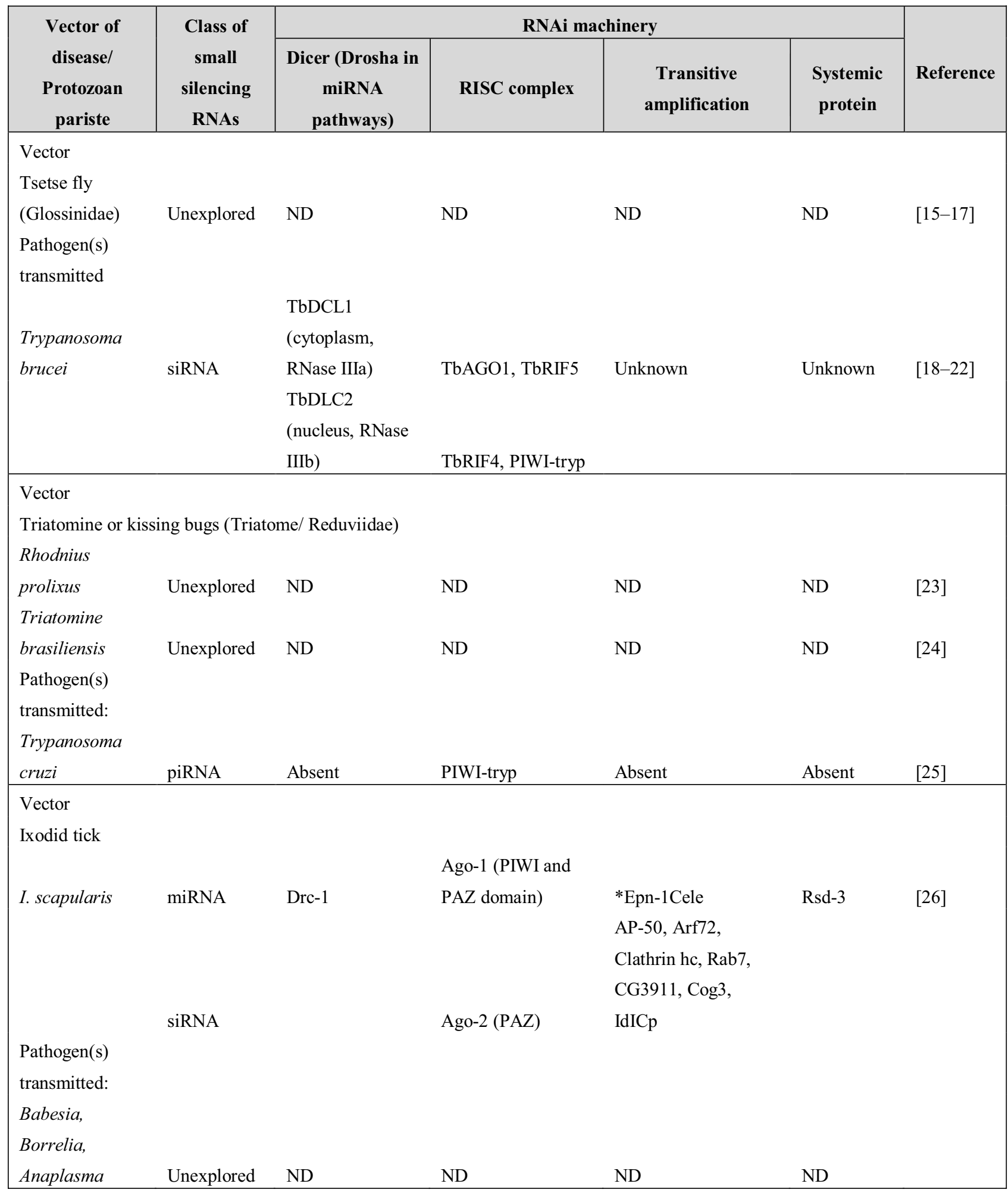


Table 2. Cont.

\begin{tabular}{|c|c|c|c|c|c|c|}
\hline \multirow{2}{*}{$\begin{array}{c}\text { Vector of } \\
\text { disease/ } \\
\text { Protozoan } \\
\text { pariste } \\
\end{array}$} & \multirow{2}{*}{$\begin{array}{c}\text { Class of } \\
\text { small } \\
\text { silencing } \\
\text { RNAs } \\
\end{array}$} & \multicolumn{4}{|c|}{ RNAi machinery } & \multirow[b]{2}{*}{ Reference } \\
\hline & & $\begin{array}{c}\text { Dicer (Drosha in } \\
\text { miRNA } \\
\text { pathways) }\end{array}$ & RISC complex & $\begin{array}{c}\text { Transitive } \\
\text { amplification }\end{array}$ & $\begin{array}{l}\text { Systemic } \\
\text { protein }\end{array}$ & \\
\hline \multirow{2}{*}{\multicolumn{7}{|c|}{$\begin{array}{l}\text { Vector } \\
\text { Mosquitoes }\end{array}$}} \\
\hline & & & & & & \\
\hline \multirow{5}{*}{$\begin{array}{l}\text { Aedes aegypti / } \\
\text { A .albopticus }\end{array}$} & & Drosha, Dicer-1 & & & & \\
\hline & miRNA & (Pasha, Loqs) & Ago-1 (x 2) & & & {$[27]$} \\
\hline & siRNA & Dicer-2, R2D2 & Ago-2 (VIG, TSN, Fmr-1) & & & \\
\hline & & & Ago-3, Ago-4 like (x 4), & & & \\
\hline & piRNA & Absent & Ago-5 like (x 3) & & & \\
\hline \multirow{5}{*}{$\begin{array}{l}\text { Culex } \\
\text { quinquefasciatus }\end{array}$} & & Drosha, Dicer-1 & & & Lack SID- & \\
\hline & miRNA & (Pasha, Loqs) & Ago-1 & & 1 , but & \\
\hline & siRNA & Dicer-2, R2D2 & Ago-2 (x 2) ( TSN, Fmr-1) & & shows & \\
\hline & & & Ago-3, Ago-4 like (x 3), & & systemic & \\
\hline & piRNA & Absent & Ago-5 like (x 3) & & response & \\
\hline \multirow{5}{*}{$\begin{array}{l}\text { Anopheles } \\
\text { gambiae }\end{array}$} & & Drosha, Dicer-1 & & & & \\
\hline & miRNA & (Pasha, Loqs) & Ago-1 & & & \\
\hline & siRNA & Dicer-2, R2D2 & Ago-2 (Fmr-1) & & & \\
\hline & & & Ago-3, Ago-4 like, Ago-5 & & & \\
\hline & piRNA & Absent & like & & & \\
\hline \multicolumn{7}{|l|}{$\begin{array}{l}\text { Pathogen(s) } \\
\text { transmitted: }\end{array}$} \\
\hline Plasmodium & Absent & Absent & Absent & Absent & Absent & {$[28,29]$} \\
\hline
\end{tabular}

The first step in allowing non-cell-autonomous RNAi is the uptake of the dsRNA, followed by an RNAi initiating step. It involves the binding of an RNA-specific nuclease to a dsRNA fragment and its cleavage into smaller double stranded small RNAs, usually of either the interfering (siRNA, from exogenous long dsRNA precursors) or miRNA (triggered by endogenous stem-loop pre-miRNA) type. The third step involves the loading of the small dsRNAs into a multi-nuclease complex. Finally, within this protein complex, the guide RNA strand associates with a homologous mRNA strand by conventional base paring, and the mRNA strand is cleaved and released for further degradation within the cytoplasm (Figure 1). The recent comparative genomics studies between the processes of RNAi in different invertebrate organisms and model organisms such as D. melanogaster and C. elegans have provided evidence that, even though much of the basic RNAi machinery is evolutionary conserved, several components differ, indicating that the RNAi pathway may vary substantially between different arthropod classes [26]. 
Figure 1. The RNAi process and biochemical machinery involved. Adapted from [30,31]. dsRNA is processed into short pieces (siRNA) by the endonuclease Dicer. The siRNA is loaded into the RNA-induced silencing complex (RISC) via the RISC loading complex (RLC), followed by cleavage and release of the passenger strand. The guide strand then associates with a homologous mRNA strand by conventional base paring, and the mRNA strand is cleaved by RISC and released for further degradation within the cytoplasm.

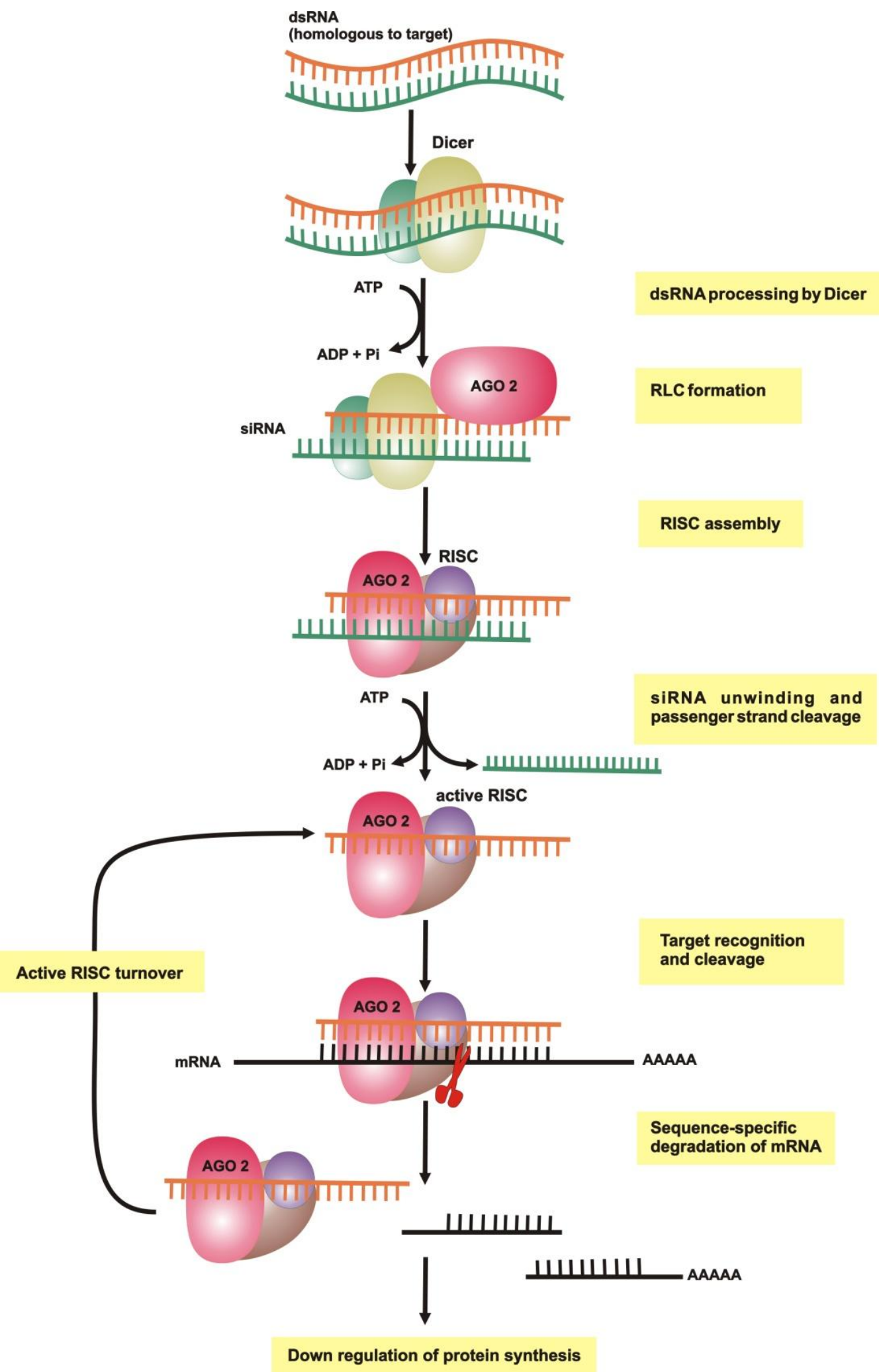




\section{1. dsRNA Uptake}

Initiation of the RNAi pathway takes place once dsRNA is present within the cell [32]. In the case of artificially introduced exogenous dsRNA, two mechanisms of dsRNA uptake have been described in invertebrates: transmembrane channel-mediated uptake through orthologs of the multi transmembrane protein SID-1 (systemic RNA interference deficient-1) of C. elegans and an endocytosis-mediated uptake mechanism [33].

SID-1 is a non-specific dsRNA transporter, engaged in the passive transport of dsRNA into cells and the spread of an RNAi response throughout an entire organism (systemic RNAi) [34,35]. This transporter protein is surface-expressed and displays diffusion-limited dsRNA transport that is energy independent. Recent evidence shows that SID-1 is instrumental in the import of silencing signals in C. elegans but not for export to neighboring tissues [36], and cells that are known to be refractory to gene silencing with exogenous dsRNA have been shown to be SID-1 deficient. Expression of SID-1 in these cells facilitated dsRNA uptake and subsequently an RNAi response [37]. While homologs of SID-1 have been reported in numerous organisms ranging from humans to various insects, they are noticeably absent from the genomes of others such as $D$. melanogaster, and this absence seems to correlate with a lack of a strong systemic RNAi response [34,38].

Endocytosis as an uptake mechanism originated from the observation that D. melanogaster cells do not express SID-1 but are still able to internalize exogenous dsRNA. Studies of Drosophila S2 culture cells resulted in the identification of several factors necessary for dsRNA uptake, of which many are also implicated in endocytosis [39]. Owing to the fact that the RNAi response was weakened by blocking endocytosis via pharmaceutical agents, the role of endocytosis in RNAi is evident [40]. Uptake experiments with FITC-labeled dsRNA conducted by Saleh et al. (2006) also showed that dsRNA molecules associate with vesicles for receptor-mediated endocytosis, with components such as vacuolar $\mathrm{H}^{+}$ATPases and scavenger proteins participating. It appears as if $\mathrm{H}^{+}$ATPase plays a crucial role in catalyzing an endocytic pathway for successful RNAi induction. Two scavenger receptors, Eater (which mediates phagocytosis of bacterial pathogens) and Sr-CI (a scavenger receptor class C, type I protein) facilitate uptake of over $90 \%$ of the dsRNA in D. melanogaster [39], demonstrating that receptor-mediated endocytosis a major avenue. The involvement of endocytosis in the uptake of dsRNA in C. elegans is also apparent with various "uptake-genes" being involved. RSD3 (RNAi spreading defect 3) seems to be involved in uptake via its ENTH-domains (Epsin N-terminal homology domain), which have been linked to several intracellular trafficking events [33].

\subsection{Initiation of $R N A i$}

The goal of the initiator step is to generate siRNAs from dsRNA. When exploiting RNAi as a reverse genetic tool, the process is artificially induced by the delivery of a dsRNA trigger. In non-mammalian systems long dsRNA ( $>200 \mathrm{bp}$ ) homologous to the target gene effectively triggers RNAi. In mammals, however, the introduction of dsRNA longer than $30 \mathrm{bp}$ results in the activation of an anti-viral interferon response, which causes systemic non-specific inhibition of translation. Therefore in mammalian systems short synthetic siRNAs or DNA constructs, which express short hairpin RNAs (shRNAs), are typically used [41,42]. Since the specificity of RNAi depends 
on the sequence and structure of the siRNAs [30], it is of great importance to carefully design the dsRNA or shRNA-constructs in order to maximize silencing of the target gene and ensure minimal off-target effects.

The introduction of long dsRNAs into non-mammalian cells cause it to be processed into 21-25 nt double stranded RNAs (siRNAs), which have characteristic structures indicative of ribonuclease III (RNase III) cleavage $[14,43,44]$. Hannon and colleagues identified and demonstrated that the enzyme responsible for the initiation of RNAi in Drosophila is in fact an RNase III-like protein and owing to its biochemical function, named the enzyme Dicer $[45,46]$. Dicer acts as a monomer: the two ribonuclease III (RNase III) domains form a single processing center by assembling into a pseudo-dimer producing 2nt 3'-overhangs [47]. Dicer preferentially processes dsRNA from the ends of the substrates, with the Piwi/Argonaute/Zwille (PAZ) domain characterizing the 3'-overhangs [48-51]

More profound insight into the structural mechanism used by Dicer came from the crystal structure of a Dicer protein derived from the protozoan Giardia intestinalis [52]. This structure revealed that Dicer attains an elongated shape and by this means acts as a molecular ruler, measuring the distance between the terminal-binding PAZ domain and the active site, thereby giving rise to the 21-25 nt products [52-54]. Although the structure and mechanism of G. intestinalis Dicer has been studied in detail, much less is known about Dicer proteins from higher eukaryotes [55]. Furthermore, G. intestinalis Dicer is an atypical Dicer in that it is much smaller and simpler than that found in any other organism to date, containing only the two RNase III domains and a PAZ domain. For example, human Dicer $(219 \mathrm{kDa})$ is nearly three times larger than that of G. intestinalis ( $82 \mathrm{kDa})$. The difference in molecular mass is accounted for by at least five additional protein domains found in most Dicer proteins [55]. These include a TAR RNA-binding protein (TRBP) [56], an amino terminal DExD helicase-like domain [57], a putative dsRNA-binding domain (dsRBD) named DUF283 [58], an Argonaute-binding domain [59] and a C-terminal dsRBD [60]. These additional domains participate in dsRNA processing, regulate dicing activity and serve as molecular scaffolds for consolidating protein factors involved in the initiation of RNAi [55].

\subsection{RNA-Induced Silencing Complex (RISC) Assembly}

Once a dsRNA trigger has been processed into siRNAs, the guide strand is identified and loaded into an effector ribonucleoprotein complex, the RNA-induced silencing complex (RISC). Since siRNAs cannot catalyze any reaction by themselves, RISC assembly is a key process for these small RNAs to exert their function [61]. To date, a complete understanding of the exact mechanism underlying this process remains elusive. Based on several in vitro studies of RISC assembly using D. melanogaster extracts and siRNAs as substrates, together with new structural studies of Argonaute (Ago), a revised 2-step model of the main features of this process has been proposed [62,63]. The first step, known as RISC-loading, involves the insertion of the siRNA duplexes into the Ago-protein. The second step entails the dissociation or unwinding of the passenger strand from RISC [61].

It is postulated that Dicer and a dsRNA binding partner (e.g. in D. melanogaster these are Dicer-2 and R2D2) are bound to the double stranded siRNAs, to direct them to the RISC complex [64]. Current findings suggest that Dicer-2 and R2D2 form a heterodimer that binds the siRNA, with Dicer binding the thermodynamically less stable end of the siRNA and the dsRBD domain binding the more 
stable end $[61,65]$. These thermodynamic and binding asymmetries appear to determine which strand is finally incorporated into RISC. The guide strand is always the strand whose 5' end is less tightly paired to its complement, implying the strand with the least thermodynamically sTable 5' end [66,67]. Once the Dicer/dsRBD/siRNA ternary complex is formed it assembles with Ago-protein to form a RISC loading complex (RLC), which is an intermediate from which Dicer/dsRBD is gradually displaced by the Ago-protein to form pre-RISC $[61,64,65,68,69]$. Once bound to the siRNA duplex, Ago cleaves the passenger strand, triggering its dissociation [70]. After discharge of the passenger strand, possibly in an ATP-dependent step, the guide strand is in close association with Ago, forming a fully mature RISC, also referred to as siRISC [61,64,65,71].

\subsection{Slicing or Silencing Steps}

In D. melanogaster, several RISC components have been identified, but only a few have been characterized at the functional level [72]. From current findings it is evident that RISC consists of several proteins and RNA molecules that act as key actors of RNAi promoting mRNA degradation, repression of translation and remodeling of chromatin structure [73]. The central catalytic component of RISC, Argonaute 2, was the first to be identified [74]. Argonaute proteins are characterized by two conserved domains: the PAZ (also present in Dicer) and PIWI domains [75]. Based on a higher degree of homology to either Arabidopsis AGO-1 or Drosophila PIWI, this family of proteins is subdivided into two highly conserved subclasses [76]. Recently an additional subclass, C. elegans-specific group 3 Argonautes, has been identified [77]. Other components which have been identified as part of the RISC-complex include the Vasa intronic gene (VIG)-RNA binding protein, helicase proteins, Tudor- staphylococcal nuclease (Tudor-SN) and Fragile X -protein (dFXR) homologs [78,79]. To date most of these proteins remain functionally uncharacterized, however. Due to the lack of structural data, the exact catalytic mechanism of target mRNA cleavage remains unclear.

In the RISC complex the 3' end of the siRNA guide strand is bound by the PAZ domain, while the PIWI domain contacts the 5' phosphorylated end [49,50]. Structural studies of prokaryotic Ago-like protein in complex with siRNA-mimics demonstrated that the sugar-phosphate backbone of the 5' end of the guide strand (nucleotide 2 to 8 ) contacts the PIWI domain in such a manner that bases 2 to 8 are presented on the surface [80,81]. This region is known as the 'seed' region [14]. Corresponding mRNA targets are initially bound by the seed region of the siRNA and then pairing is extended to the 3' end. A single cleavage of the target mRNA occurs across from nucleotide 10 and 11 (with respect to the 5' end) of the guide stand. The catalytic engine is an RNaseH fold present in the PIWI domain [75,81,82]. Although target cleavage by Argonaute does not require ATP per se, release of the cleaved target (RISC recycling) is stimulated by ATP [83,84]. From in vivo studies it is evident that, once released from RISC, the 3' mRNA fragment is degraded in the cytoplasm by exonuclease Xrn1, while the 5' fragment is degraded by a complex of exonucleases, the so-called exosome [85]. In the RNAi pathway, siRISC operates as a multiple turn-over enzyme. Once the mRNA target is cleaved, siRISC dissociates from the cleaved mRNA to repeat another cleavage cycle [30].

In plant and nematode species it has been described that the RNAi signal is amplified by an RNA-dependent RNA polymerase (RdRP), which results in a systemic RNAi effect that can spread from the targeted/treated tissue to other tissues [86]. To date, this RdRP-dependent RNAi 
amplification seems absent in higher eukaryotes, and even from D. melanogaster and mosquitoes. However, based on several RNAi studies in ticks it is evident that this phenomenon does occur in ticks, since application of dsRNA (via body cavity injection, feeding or soaking) results in global and persistent gene silencing in both treated ticks and their progeny [87-90]. Recent preliminary studies have indicated that this systemic RNAi effect in ticks is most likely attributed to a tick RdRP homolog [26].

In order for RNAi to spread from one cell to another a transport system is required. In C. elegans several proteins, necessary for systemic RNAi have been identified. These include a multi transmembrane protein SID-1 (systemic RNA interference deficient-1(sid-1)) thought to act as a channel for dsRNA uptake [34], as well as RNAi spreading defective proteins (RSD2, RSD3, RSD6) [91]. To date only RSD3 and Endocytic protein (Epn-1) have been identified in ticks, leaving the mechanism of cell to cell dsRNA transport in ticks unresolved. Although more components of the tick RNAi machinery have been identified, the exact mechanism remains to be determined [26]. The current model for most invertebrate parasites RNAi is based on integrated knowledge of the RNAi process of model/other organisms including, D. melanogaster, C. elegans and mosquitoes (Figure 2).

\subsection{Transitive Amplification of the Initial dsRNA Signal}

In various plant and nematode species it has been found that the silencing signal is amplified by a process reliant on a RNA-dependent RNA polymerase (RdRP), which in effect permits a systemic RNAi response from the site of origin to eventually most or all other tissues [26,86]. A two-step mechanism has been described for RdRP amplification in C. elegans [92]. Once the primary siRNA has been generated by Dicer, RdRP uses the guide siRNA strand as primer and native mRNA as template to synthesize abundant secondary siRNAs and increasing the effectiveness of RNAi (Figure 2). As RNA synthesis occurs in a 5'-3' direction, this amplification leads to the 5' spreading of the initial RNA interference signal. This phenomenon is known as transitive RNAi [92].

To date RdRP-dependent RNAi amplification seems absent in D. melanogaster, many other insects and higher eukaryotes. Interestingly, a putative homolog of the RdRP EGO-1 protein from C. elegans has also been identified in the tick species I. scapularis. This protein is associated with the amplification of trigger RNA by transcribing additional dsRNA molecules using target mRNA as a template, thereby yielding secondary siRNAs and increasing the effectiveness of RNAi [40,93]. RdRPs appear to be absent in other metazoans except for several nematodes and a lancelet (Branchiostoma floridae) [94]. The tick RNAi pathway may therefore differ from that of other arthropods, but more research is required to clarify the exact RNAi mechanism.

\subsection{Systemic RNAi}

In order for RNAi to spread from one cell to another a transport system is required. The phenomenon of the progression of an RNAi response from the site of origin to neighboring cells and eventually to all, or most, tissues of the organism was first described in plants and C. elegans. The systemic response may even persist through multiple developmental stages, including being transferred through the germline to the progeny. It has been proposed that this response has evolved as a strategy to increase the silencing efficiency [95] and it is known to form part of the immune system in plants. 
For the functioning of a robust systemic response there are three essential steps: firstly the uptake of an extracellular dsRNA signal into a cell, secondly the amplification and distribution of the said signal to other cells, followed by a successful degradation or blocking of a homologous mRNA transcript [38].

Figure 2. A schematic representation of a putative RNAi pathway for invertebrate pathogens and vectors. The proposed model might either use a multi trans-membrane protein (similar to SID-1) for dsRNA uptake or an endocytosis-mediated process which may include scavenger receptors. Once the dsRNA is in the cytoplasma it is processed into siRNAs $\sim 21-23 \mathrm{nt}$ in length, by a Dicer homologue. The siRNA are then presented to RISC which incorporates the siRNA, targets and degrades any homologous mRNA. RISC includes Ago, TudorSN and FmRp homologues. The proposed activity of RdRP is indicated as amplifying either trigger dsRNA, cleaved siRNA or using primary siRNA to prime synthesis of secondary siRNAs utilizing native mRNA as template. This causes 5, amplification and spreading of the initial RNAi signal, and is known as transitive RNAi.

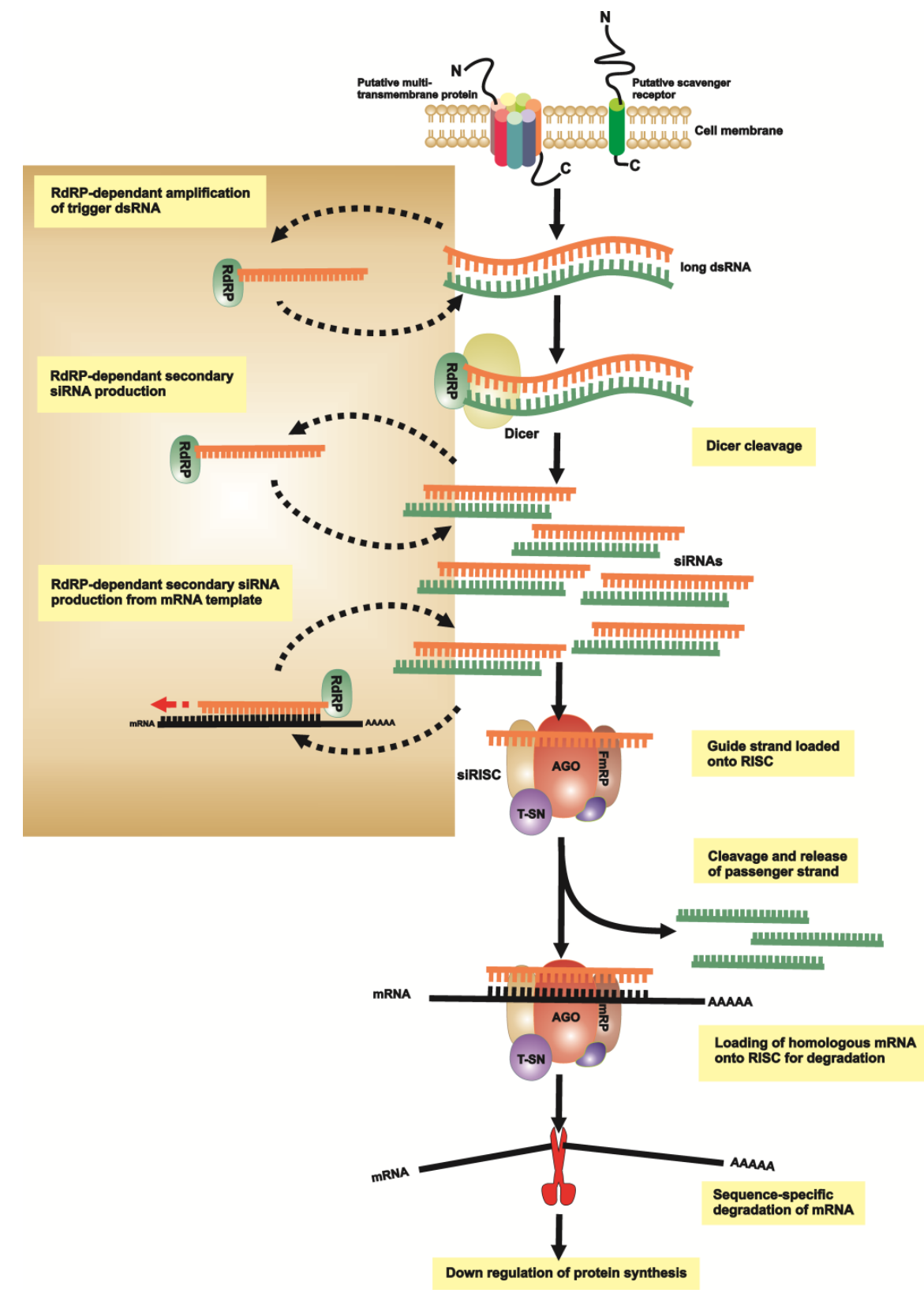


Although the exact mechanisms pertaining to a systemic RNAi response remain unclear, many benefits associated with its presence makes it a highly desirable feature in organisms investigated using RNAi. Firstly, the amplification of the introduced RNAi signal means that lesser/smaller amounts of dsRNA can evoke the needed response throughout the entire organism. Secondly, the fact that silencing is spread and effected throughout all tissues makes target gene selection of the whole genome of the studied organism possible. This is especially relevant in those experiments where the mode of administering dsRNA cannot deliver it to all tissues, for example through oral delivery or direct injection. Another application made possible is the study of genes in life stages such as eggs that may not be amenable to other methods of dsRNA delivery. By delivering the relevant dsRNA to a preceding life stage, in this case the adult female, systemic RNAi will propagate the necessary signal throughout the adult as well as within any eggs produced by that female [88]. This application is known as parental, trans-stadial or transovarial RNA interference. Exploiting systemic RNA interference during RNAi studies is also a relatively simple procedure. For these reasons there is a definite advantage and incentive to elucidate the complete mechanism of systemic RNAi so that it could be induced experimentally in organisms that do not show a systemic RNAi response themselves.

Although more pieces of the RNAi machinery of different disease vectors and pathogens have been identified, the exact mechanism of each remains unknown. Current RNAi models for most invertebrate parasites is based on integrated knowledge of the RNAi process of model/other organisms including D. melanogaster, C. elegans (Figure 2).

\section{RNAi of Lice, Ticks and Tick-Borne Pathogens}

\subsection{RNAi Pathways and Methodologies}

Apart from model organisms such as Drosophila, ticks have provided us with a significant understanding of RNAi in arthropod vectors of disease and hence will be discussed in a bit more detail in this section. Ticks are obligate hematophagous parasites and are important vectors of a wide variety of pathogens including viruses, protozoa and bacteria which affect human and animal health worldwide [96]. Elucidating tick-host-pathogen interactions is of interest for the development of novel intervention strategies such as anti-tick and pathogen-transmission blocking vaccines to limit the damage caused by ticks and prevent the spread of pathogens. The increasing availability of genomic data from tick-borne pathogens and ticks such as Ixodes scapularis and Rhipicephalus (Boophilus) microplus has introduced a new era in tick research and greatly advanced studies addressing tick biology and host-vector-pathogen interactions [97-99]. The possibility to silence the expression of genes in ticks using RNA interference (RNAi) has proven to be pivotal in numerous studies which focus on deciphering tick gene function. Since the first report of an RNAi experiment in Amblyomma americanum ticks in 2002 [100], this method has been applied successfully in other hard ticks belonging to the Amblyomma, Dermacentor, Haemaphysalis, Ixodes, and Rhipicephalus genera and in Ornithodoros soft ticks [101-103].

Mites belong to the same subclass as ticks (Acari) and may also act as vectors of disease, albeit to a lesser extent. The most important mite-borne disease of humans is scrub typhus (Orientia tsutsugamushi), which is primarily transmitted by several members of the genus Leptotrombidium. 
Parasitic mites living on or burrowing in the skin may also cause dermatitis in humans and animals. The full genome of the two-spotted spider mite Tetranychus urticae, a plant-feeding mite, was recently published and is the first chelicerate genome to be completely sequenced [104]. Successful gene silencing by RNAi has also been described for this mite and the honey bee mite Varroa destructor $[105,106]$.

Two mechanisms of dsRNA uptake have been described in arthropods: a transmembrane channel-mediated uptake through orthologs of the SID-1 protein of C. elegans and an endocytosis-mediated uptake [33]. As SID-1 is not present in tick and mite genome sequence databases, an endocytosis-mediated uptake is hypothesized in Acari. In the endocytosis-mediated uptake of dsRNA in Drosophila, scavenger receptors are thought to mediate dsRNA uptake [39,40]. Evidence for an endocytosis mediated mechanism for dsRNA uptake with an essential role for a scavenger receptor in ticks was recently provided by an 'RNAi of RNAi' approach. When the expression of HISRB, the class B scavenger receptor CD36 from Haemaphysalis longicornis, was silenced $96 \mathrm{~h}$ before dsRNA coding for a second target gene ( $H l V g-1$ or $H l V g R$, encoding vitellogenin and vitellogenin receptor) was introduced, subsequent knockdown of the second gene was inhibited. A double knockdown of target genes could however be observed when HISRB was silenced 96h after the knockdown of $H l V g-1$ or $H l V g R$ [93]. This suggests that receptor-mediated endocytosis is also relevant for systemic RNAi in ticks, with an essential role for scavenger receptor class B. Orthologs of the class B scavenger receptor CD36 within the superorder Parasitiformes have been annotated for I. scapularis (GenBank Accession number XP002409323) and the western predatory mite Metaseiulus occidentalis (XP003743396). Other key components of intracellular RNAi were recently identified from tick and mite genomic sequence databases by homology searches [26,104]. These include putative Dicers responsible for the cleavage of dsRNA to siRNAs, Argonaute proteins which function as the catalytic component of RISC and others (Table 2).

RNAi is usually accomplished by treatment of ticks, tick tissues, tick cells or mites with dsRNA, but the successful use of siRNA to silence gene expression in these specimens has also been reported [106-109]. Most laboratories transcribe dsRNA in vitro from a PCR template which has been amplified using primers containing a $\mathrm{T} 7$ promoter sequence. The relative simplicity of synthesizing dsRNA and its high efficacy have made it the most commonly used mediator in tick RNAi studies. A drawback of the use of long dsRNA is that it increases the chance of causing off-target effects (OTE), leading to false discovery. OTE are caused by species-specific recognition of transcripts other than the intended target. This can be addressed in the experimental design by preventing the use of dsRNA sequences of which nucleotide stretches may recognize non-target transcripts. Various in silico prediction algorithms to analyze possible OTE have been described [110,111] but their application in tick research is frustrated by the absence of full tick genome data. The use of siRNA, small dsRNA (100-200 bp) or of two non-overlapping dsRNAs per gene to assess whether both induce the same phenotype, may limit the occurrence or facilitate the detection of OTE [110,112]. However, these strategies have thus far found only limited adaptation in tick research using RNAi.

The injection of dsRNA into the hemacoel via the ventral exoskeleton surface using fine-gauge or pulled capillary needles is the most commonly used delivery method for dsRNA in ticks. After a recovery period to monitor for tick mortality resulting from the injection, ticks are fed on experimental animals or an artificial feeding system [100,113]. Parameters such as tick mortality, tick weight after 
feeding and the amount of eggs oviposited can subsequently be recorded to evaluate the effect of gene silencing on general tick function. Biological material such as hemolymph or saliva and tissues can furthermore be collected for further analysis in functional assays and histological examination [114-117]. By injecting dsRNA into the hemocoel of freshly engorged female ticks through the spiracular plate, gene silencing can be established in the eggs and larvae hatching from these eggs [88,118,119]. A similar method can be used to silence genes in the eggs of mites [106]. The spread of dsRNA to different tissues following injection in the hemacoel demonstrates that RNAi is systemic in the Acari lineage.

Infection of the $I$. scapularis cell line ISE6 with the a recombinant Semliki Forest Virus replicon expressing heterologous Nairovirus sequences induced siRNAs which inhibited the replication of Hazara virus, a Nairovirus, by RNAi in this cell line [120]. Besides this viral delivery, the incubation with dsRNA or siRNA is also effective in establishing gene silencing by RNAi in tick cells. Optimum conditions were however shown to vary for different cell lines. DsRNA was more efficient for gene silencing by RNAi in tick cells than siRNA and use of the latter requires a transfection reagent [121]. RNAi can also be used to study the effects of gene silencing on tissue function ex vivo following the immersion of dissected tissues in a dsRNA solution [113,122,123]. Overnight soaking at $4{ }^{\circ} \mathrm{C}$ in a $0.9 \%$ saline solution containing dsRNA at a concentration of $2,5 \mu \mathrm{g} / \mu \mathrm{L}$ has been applied successfully to establish gene silencing in whole Varroa destructor mites. The addition of $\mathrm{NaCl}$ was apparently necessary as soaking in plain water containing dsRNA was not effective [105]. The soaking of whole ticks, which would reduce the laboriousness and mortality associated with injections and simplify dsRNA delivery especially in juvenile tick stages, has also been reported for Haemaphysalis longicornis nymphs but requires further optimization [124]. Soaking of eggs and nymphs in combination with electroporation was successfully used for dsRNA delivery in I. scapularis ticks [125].

Further evidence for the occurrence of systemic RNAi in ticks was provided by Soares et al., who delivered dsRNA to I. scapularis nymphs using capillary feeding of a dsRNA solution. Ingested dsRNA targeting an anticomplement gene (isac) in the salivary gland spread via the gut to the target organ, where it resulted in a knockdown of isac expression [89].

\subsection{RNAi to Understand Tick Vector Biology}

RNAi has also helped to unravel the molecular complexity of tick physiology and biology. Hard ticks for example concentrate their blood meal during feeding by secreting excess water imbibed with the blood back into the host with saliva. A water channel or aquaporin (AQP) was found to be expressed in the gut and salivary glands, organs which are associated with a high water flux. Gene silencing of AQP in I. ricinus females by RNAi disrupted the water passage from gut to salivary glands, resulting in an accumulation of blood in the gut which could not be concentrated. The gut subsequently became too full to accommodate more blood and the total blood volume ingested was significantly reduced. The hemolymph osmolarity consequently increased and fluid secretion by isolated and ligated salivary glands was abolished [113]. Other examples of biological and physiological processes which have been studied in ticks include blood feeding [89,115,124,126-131], blood digestion [132,133], iron metabolism [134], reproduction [135,136] and innate immunity [137]. 
Another interesting application of RNAi in ticks is its use as a tool to screen for tick protective antigens which may be suitable anti-tick vaccine candidates [138,139]. In these screens, dsRNA is transcribed from individual clones of a cDNA library and screened in increasingly smaller pools for their effect on tick feeding and survival. This may result in the identification of proteins that are critical for the tick which can subsequently be evaluated as potential vaccine antigens. By using this approach, researchers could identify subolesin, a protein which was shown to have efficacy as a recombinant antigen in vaccination trials against various tick species, the poultry red mite Dermanyssus gallinae, mosquitoes and sand flies [140].

Silencing of subolesin produces ticks with diminished reproductive performance which prevents successful mating and the production of viable offspring. The release of subolesin-silenced ticks, alone or in combination with subolesin vaccination, was proposed as an alternative tick control strategy $[119,141]$. Although interesting, many questions concerning the feasibility and consequences of this approach, such as the reduced fitness of modified ticks and the ecological impact of their release, remain to be answered before this or similar methods can be put into practice.

Injection of adult female mites or engorged female ticks with dsRNA results in gene silencing in their offspring, a phenomenon which is also known as 'parental' or 'transovarial' gene silencing $[88,106,118]$. Parental RNAi may be used to study the function of genes in embryogenesis and will facilitate studies in evolutionary developmental biology, an area of tick and mite research which lags behind that of many other invertebrates.

\subsection{RNAi to Understand Tick-Pathogen Interactions}

To study tick-pathogen interactions, a typical experimental approach starts with the identification of tick genes which are differentially expressed when ticks are infected with a pathogen. Techniques such as suppression subtractive hybridization (SSH) [142], two-dimensional (2-D) gel electrophoresis [143], 2-D fluorescence difference gel electrophoresis (DIGE) [127], RT-PCR [144] and microarrays [145] have been used for this purpose. The differential expression is usually confirmed by (semi-)quantitative RT-PCR. The expression of genes which are found to be up-regulated following infection can subsequently be silenced by RNAi to study the effect of gene knockdown on the course of the infection. This approach was for instance followed to identify tick salivary gland proteins up-regulated in I. scapularis ticks in response to infection with Borrelia burgdorferi, the causal agent of Lyme disease of which I. scapularis is the predominant vector in North America. DIGE coupled with mass spectrometric analysis using extracts from B. burgdorferi-infected and uninfected salivary glands led to the identification of a histamine release factor $(t H R F)$ which was strongly up-regulated in the salivary glands of $B$. burgdorferi-infected ticks during engorgement. Gene silencing of tHRF in B. burgdorferi-infected nymphs impaired successful feeding and resulted in reduced spirochete levels in ticks and the mice they had fed upon. It is suggested that the decreased feeding ability of tHRF-deficient ticks may have disrupted the B. burgdorferi replication and dissemination inside the ticks, reducing the efficiency of spirochete transmission [127]. The laboratory of Erol Fikirg, also identified 14 different salivary gland proteins (salp) which are secreted into the host during feeding, by probing an $I$. scapularis salivary gland cDNA expression library with serum from tick-immune rabbits [146]. The expression of two of these genes, salp15 and salp16, was found to be selectively 
increased in I. scapularis ticks infected with B. burgdorferi or A. phagocytophilum, respectively $[144,147]$. Gene silencing of salp15 and salp16 did not impair tick feeding as tHRF did, but did interfere with the pathogen life cycle. While the B. burgdorferi levels in the salivary glands of control and salp15-deficient ticks were similar, the spirochete burden was significantly lower in the mice on which salp15-deficient ticks had fed. This demonstrated that Salp15 facilitates tick-borne B. burgdorferi infection in the host [147]. Silencing the gene expression of salp16 inhibited the acquisition of $A$. phagocytophilum by the vector tick from infected mice. Pathogen levels in the gut of control and salp16-deficient ticks which had fed on infected mice were similar, but the $A$. phagocytophilum levels in salivary glands were significantly lower in salp16-silenced ticks, suggesting that A. phagocytophilum requires salp16 to infect the salivary glands [144]. Other functional analysis studies based on RNAi which focused on the tick immune responses have also identified genes which may be involved in the vectorial capacity of ticks for a variety of pathogens [114,142,148,149]. These examples demonstrate the intimate relationships between vector-borne pathogens and their arthropod hosts on which RNAi shed light.

\subsection{RNAi in Phthiraptera (Lice)}

Lice are obligate ectoparasites of mammals and birds which may feed on blood (bloodsucking lice of the suborder Anoplura) or on skin debris, hairs and feathers (chewing lice). Three Anoplura species are ectoparasites of humans: the head louse (Pediculus humanus capitis), the human body louse (Pediculus h. humanus) and the crab louse (Phthirus pubis). Of these three, only the body louse is a vector of pathogens, including the causal agents of epidemic typhus (Rickettsia prowazekii), trench fever (Bartonella quintata) and louseborne relapsing fever (Borrelia recurrentis) [150]. The genome of the body louse was recently sequenced and is with $108 \mathrm{Mb}$ the smallest insect genome known to date [151]. A gene-specific reduction in transcript levels following the injection of dsRNA in female lice was recently reported [152] and key components of the RNAi pathway have also been identified in the human body louse genome [150]. Their small genome size, the presence of a functional RNAi pathway and differences in their ability to transmit pathogens make the head and body louse interesting models for comparative functional genomic studies to unravel the molecular mechanisms which determine vector competence [150].

\section{RNAi of Mosquitoes and Their Associated Pathogens}

Only a few mosquito species are vectors of pathogens that cause serious disease. Anopheles gambiae is the primary vector for the malaria parasite Plasmodium falciparum. Aedes species are responsible for potentially fatal encephalitis and hemorrhagic fevers caused by Dengue and Yellow fever viruses and certain Culex species transmit West Nile virus and nematodes that cause filariasis in humans (Table 1). The capacity of mosquitoes to serve as vectors revolves around a number of essential behavioral and biological factors, such as their preference for blood-feeding, their high susceptibility to parasite infection and their longevity [153]. Some of the most important vector species require multiple blood meals during each egg-laying cycle, thereby increasing the risk for pathogen transmission [154]. 


\section{1. dsRNA Introduction into Mosquitoes}

RNAi-based silencing of gene expression has been achieved in mosquitoes using a number of different dsRNA delivery methods. In the majority of studies to date, in vitro synthesized dsRNA have been injected directly into the mosquito hemolymph. Those that survive the micro-injection procedure are then fed or exposed to the relevant physiological condition and/or stress factors and evaluated for the phenotypic effect caused by knockdown of the target gene. In mosquitoes, these often relate to effects on certain aspects of fecundity such as oviposition and egg development, or physiological evidence of cell damage, insect mortality or behavioral changes (reviewed in $[155,156]$. The micro-injection procedure, however, is not optimal or efficient particularly in light of the mosquito's small size. One alternative is to use oral introduction, as demonstrated in a study where chitin synthase-targeted dsRNA was fed to An. gambiae larvae, resulting in significant mortality [157]. Another is by topical application of dsRNA, demonstrated in Ae. aegypti adults [158]. In a first, Coy et al. recently demonstrated that knockdown can be achieved in adult mosquitoes by the oral delivery of dsRNA via a liquid sucrose meal. The dsRNA was ingested by adult females and caused a reduction in the level of transcription of the vacuolar ATPase gene target [159]. A recombinant densovirusmediated RNA interference system has also recently been developed for both in vitro and in vivo use [160]. The efficiency of RNAi has been shown to differ between tissue types, with midgut tissues and hemocytes being amenable to effective knockdown whereas inhibition of genes in the salivary glands required much higher dosages of dsRNA. Nonetheless, the larger quantities appeared to not compromise the silencing specificity [161]. Details of the uptake mechanism of exogenously added dsRNA and its subsequent processing has not been resolved yet, but processing is thought relate to the intrinsic virus-mediated RNAi response of mosquitoes (summarized below and reviewed in [33,162].

\subsection{RNAi to Understand Mosquito Vector Biology}

Functional studies using RNAi have provided a significant amount of insight into vector biology, such as integrated pathways that respond to hormonal and nutritional signals affecting feeding, vitellogenesis and egg production [153,163-167]; factors involved in lipid biosynthesis [168], vesicle transport between the ER and Golgi [169], steroid metabolism [166,170,171]. A large portion of literature also addresses olfaction in mosquitoes that influences aspects of their behavior, such as host seeking, feeding, mate selection and location of appropriate breeding sites [172,173]. Erdelyan and colleagues (2012) identified two $\mathrm{CO}_{2}$ receptor genes, AaGr1 or AaGr3 that upon knockdown resulted in a loss of $\mathrm{CO}_{2}$ sensitivity in Ae. aegypti and Culex pipiens quinquefasciatus mosquitoes, impacting host detection. Interruption of the olfactory system could be used to design compounds that disrupt the mosquito's ability to find a host, thereby limiting the potential for pathogen transmission [174].

\subsection{RNAi as a Tool for Studying Mosquito Vector-Pathogen Interactions}

Initial studies supporting RNAi-based gene silencing as a suitable tool for understanding the vector-pathogen interface in mosquitoes, include Dengue virus (DENV) replication inhibition by transfection of an Aedes albopictus cell line using DEN1- and DEN2-specific dsRNAs [175,176] and knockdown of the antimicrobial gene defensin by in vivo injection of gene-targeted dsRNA into the 
thorax of adult Anopheles gambiae [177] . A different approach [178], where dsRNA was expressed in situ from a transgene stably integrated into the mosquito genome and designed to transcribe an intron-spliced RNAi hairpin loop from an upstream promoter, have also become of great use. A myriad of studies have been reported, with most using direct delivery of dsRNA rather than the more demanding approach of transgenesis.

With regard to viral transmission by mosquitoes, the long-standing view that mosquito innate immunity likely plays a role in restricting virus replication has been addressed in a number of studies. Based on the knowledge of immunity in D. melanogaster, orthologs of genes encoding Dcr2, R2D2 and Ago2, components of the intrinsic arthropod RNAi pathway, were silenced in a number of independent studies. Suppression of the mosquito RNAi defense mechanism resulted in an increase of alphavirus- and DENV replication in Aedes aegypti cultures and mosquitoes [27,179] and O'nyong-nyong replication in Anopheles gambiae [180]. These and other studies have provided clear evidence that RNAi is the major defense mechanism against arbovirus infections [181]. Some evidence has also been presented that the RNAi response may be systemic. In cultured Aedes albopictus cells, direct cell-to-cell spread of an RNAi signal inhibited the replication of incoming Semliki Forest viruses [182]. A similar spreading signal has been observed in vivo in D. melanogaster but the mechanism remains to be characterized. Studies have also provided evidence for the production of virus-derived piRNAs following arbovirus infection in mosquito cells, suggesting that this pathway may be another facet of antiviral defense [183]. It has also been possible to generate DENV2-resistant Ae. aegypti mosquitoes by constitutively triggering the RNA interference pathway via long DENV-specific dsRNAs transcribed from an integrated transgene. This transgenic approach provided heritable resistance to virus replication and transmission across 17 generation [184] before expression of the effector gene was then lost for unknown reasons. This encouraging result illustrates the potential of anti-pathogen suppression using RNAi, as explained in more detail in section 7.

Microarray-based transcriptional profiling in combination with RNAi is providing new information on immune signals that respond to virus infection. In one such a large-scale study, DENV infection of Ae. aegypti mosquitoes resulted in the identification of more than 70 genes putatively associated with immune signaling [185]. Knockdown of candidates has shown that both the Toll pathway [185] and JAK-STAT pathway [186], conventionally associated with defense against bacteria and fungi, also contribute to Ae. aegypti virus responses [187,188]. A recent study by Sim and Dimopolous provided evidence that Arboviruses are capable of actively suppressing the immune pathways in cells they infect, rather than simply failing to trigger host immunity [189]. When the transcriptome of Ae. aegypti cells infected with DENV was analyzed using microarrays, the Toll pathway, as in mosquitoes, was activated. In addition, numerous immune signaling molecules and anti-microbial peptides (AMPs) were down-regulated. In a similar study, Colpitts et al. also demonstrated down-regulation of four cecropins and a defensin in Ae. aegypti mosquitoes infected with respectively DENV, WNV and Yellow fever virus [190]. The molecular details of the findings in these studies have yet to be validated by functional RNAi studies.

Finally, mammalian cells infected with DENV undergo apoptosis due to a shutting down of protein synthesis in host cells. In mosquito cells, however, apoptosis is mostly inhibited, likely to allow for the spreading of viral progeny to neighboring cells while evading host inflammatory responses [191]. Chen et al. provided evidence that mosquito cells also have strategies for protecting themselves against 
stresses induced by virus infection, such as GST that is involved in antioxidant defenses and an inhibitor of apoptosis, IAP. When GST was silenced in DENV-infected C6/36 mosquito cells, there was a higher rate of apoptosis [192]. Furthermore, silencing of IAP rendered mosquito cells highly sensitive to DENV-induced oxidative stress [193].

There is considerable interest in understanding the molecular and cellular interactions between mosquito vectors and protozoan parasites, with many studies focusing on the interaction between An. gambiae and Plasmodium species. In the past decade, RNAi approaches have been applied in numerous studies to unravel the genetic basis of the mosquito's susceptibility and the immune responses elicited by the parasite. A multitude of mosquito genes that respond to Plasmodium infection have been identified in recent years as reviewed in a number of papers [194-196]. These include genes that may either negatively influence Plasmodium development, i.e. antagonists, or have a beneficial effect on parasite development, i.e., agonists. Some of the first An. gambiae genes identified and verified by RNAi to encode anti-parasitic factors were TEP1 [197] and LRIM1 [198]. These are both pattern recognition receptors (PPRs) of the innate immune system, with TEP1 being a complement-like protein and LRIM1 a C-type lectin. RNAi-mediated silencing of TEP1 prevented melanization of parasites, a mosquito response to lower parasite load, while silencing of LRIM1 resulted in a substantial increase in oocyte numbers. APL1, a leucine-rich repeat protein was also verified as an antagonist [199]. Knockdown studies have since indicated that LRIM1 and APL1C occur as a heterodimer in the mosquito hemolymph that interacts with TEP1 [200,201]. It therefore seems as if the LRIM1/ApL1C/TEP1 complex's function is to target Plasmodium parasites for destruction.

Proteins expressed in the mosquito salivary gland that are involved in parasite invasion have also been characterized. A study of Gosh and colleagues demonstrated that interaction between the salivary-gland-specific surface protein saglin and the parasite surface protein TRAP (Thrombospondin-related anonymous protein) is essential for spoorozoite invasion. In vivo RNAi of saglin results in a strong inhibition of salivary gland invasion by parasite [202]. Many antagonists have since been discovered and their function analyzed using RNAi-based techniques. Most notably, these include the hypervariable PPR AgDscam [203], members of the fibrinogen-related protein family (FREP) [204] and the C-type lectin CLSP2 [205].

Gene silencing approaches have further shown that An. gambiae expresses proteins that protect Plasmodium from its immune defenses, or aid in their transport through membrane barriers. The C-type lectins CLT4 and CTLM2A serve as examples of immune system agonists. Gene knockdown / RNAi-mediated silencing of these genes results in massive melanization of ookinetes [198]. Some examples of mosquito proteins required for Plasmodium midgut and salivary gland invasion include AgESP, epithelial serine protease and upstream regulator of cytoskeleton remodeling [206], PRS1 (Plasmodium responsive salivary 1), a protein up-regulated in infected salivary glands [207], the antibacterial protein lysozyme c-1 [208], and hemolymph lipid transporter, ApoII/I [209]. RNAi-mediated silencing of these genes in some way caused a phenotype that validated their involvement in aiding Plasmodium invasion, reproduction and/or transmission. Proteins with properties like these are obvious candidates that merit further investigation for possible use in future anti-malaria strategies. 


\section{RNAi in Triatominae and Trypanosoma cruzi.}

Only three examples of RNAi in Triatominae can be found in the literature to date. In 2006, salivary nitrophorin 2 (NP2) was silenced and both anticoagulant and apyrase activity in saliva were affected, confirming the role of NP2 in blood coagulation [23]. Insight into embryonic development of Rhodnius prolixus was provided by RNAi of the gap-gene $R p$-gt, confirming its role in proper head and abdomen formation and that the function of $g t$ in hemipterans is more similar to that in dipterans than previously anticipated. This will be invaluable for understanding the evolution of patterning in insect embryos [210].In the closely related Triatoma brasiliensis, an intestinal thrombin inhibitor (brasiliensin) was silenced in nymphs [24,211]. Knockdown reduced both the thrombin inhibitory activity and the plasma clotting time in midgut tissue, confirming brasiliensin as a potent anti-haemostatic targeting thrombin. In addition, silencing decreased bloodmeal uptake, suggesting that anticoagulant activity in the vector midgut influences the amount of blood taken from the host. With the commencement of mass sequencing of the salivary glands of triatomines, many novel genes of unknown function have been identified and need to be evaluated as possible targets for control. With phenotypical analysis, after the introduction of dsRNA by injection or ingestion, it was evident that although the relevant machinery has not been elucidated to date, an RNAi pathway is present in $R$. prolixus allowing functional genomic studies.

Trypanosoma cruzi, the causative agent of South American trypanosomiasis / Chagas Disease, is transmitted by $R$. prolixus and is regarded as a neglected tropical disease affecting millions of people in the Americas. In contrast to its close relative, T. brucei (see section 6), T. cruzi lacks an RNAi pathway. Hypotheses on this loss of RNAi pathways are well described in a review by Lon-Fye and colleagues [212]. A valuable observation that has been made from studying protozoan parasites, such as trypanosomes, is that there seems to be a direct relationship between the absence of mobile genetic elements and RNAi pathway deficiency. This is thought to be a direct result of the decay and finally the loss of function of these elements over an extended evolutionary period. The RNAi pathway therefore ceased to offer a selective advantage in these organisms and became lost without apparent consequences [1].

There are however four approaches to study $T$. cruzi that are noteworthy. Firstly, deep sequencing and genome-wide analyses revealed a significant number of short non-coding RNAs of which 79 do not show homology to known RNA classes. This study will provide insight into alternative RNA pathways in T. cruzi [213]. Secondly, there is research conducted to identify essential components of the RNAi pathway in T. brucei and to then transfer these to RNAi-deficient pathogens such as T. cruzi, enabling RNAi studies [22]. Thirdly, a recent study by Genovesio and colleagues used RNAi from the human host perspective to gain insight into the host-pathogen interface. By means of a genome-wide RNAi screen of human genes, they identified receptors as well as genes associated with calcium release and the TGF-beta signaling pathways, all involved in T. cruzi parasite entry. This study may pave the way towards novel entry-inhibiting drug targets [214]. Lastly, the development of integrative and episomal transformation allow for reverse genetic approached to be used, as well as rescue studies in T. brucei by means of T. cruzi equivalents [215]. 


\section{RNAi in the Tsetse Fly and Trypanosoma brucei}

\subsection{RNAi Contributions to Understanding Vector Biology}

Introduction of dsRNA into tsetse flies is done via feeding of flies on dsRNA containing bloodmeals or by in vivo injection [216]. To date a vast amount of genes have been silenced in the tsetse fly to gain insight into their biological functions and contribution to vector fitness. Some examples include silencing of Lipophorin, a lipid transport protein. Silencing of Lipophorin resulted in decreased lipid levels, delayed oocyte development and extended larval gestation periods but the findings still suggest another carrier lipoprotein to also be required for these processes in the tsetse fly [16]. Disruption of a nucleotidase-related protein in the salivary glands reduced anti-thrombotic activities by some $50 \%$, confirming that nucleotidases in tsetse flies, similar to other haematophagous ectoparasites, constitute a major part of the vector's anti-haemostatic machinery [17]. RNAi studies of two milk proteins GmmMGP2 and GmmMGP3, which are essential for viviparous reproduction, identified only GmmMGP2 as the gene impacting fecundity in tsetse flies. The discrimination power of RNAi revealed that only in GmmMGP2 knock-down flies, were ovulation, oocyte accumulation and degradation disrupted and fecundity reduced [217,218].

\subsection{RNAi Contributions to Understanding Vector-Pathogen Interactions}

Noteworthy is the number of papers in which RNAi was used successfully to disentangle host-pathogen interactions between tsetse flies and the causative agent of African and animal trypanosomiasis, T. brucei. In the past five years, the following insights have been gained: (1) Tsetse ALBA RNA-binding proteins are involved in trypanosome development in vivo [219]; (2) The EP protein is a potent immune-responsive molecule in the tsetse fly capable of reducing T. brucei infection in the vector midgut [15,220]; (3) Although 16 small Rab GTPases are present in T. brucei, three Rab proteins RabX1-3 are novel and play a role in fly infectivity [221]; (4)The bacterial endosymbiont of the tsetse fly, Wigglesworthia glossinidiae, actually protects the vector from being invaded by $T$. brucei. The interaction between the tsetse peptidoglycan recognition proteins, the bacteria, the level of anti-microbial peptides in the vector, and the mechanism of action are well described [222]. Finally, silencing of transferrin in the fat body tissues of tsetse flies increased the number of trypanosome infections, indicating a role for transferrin in protecting tsetse flies against infection [15].

One paper on understanding the host-vector interactions was published by Caljon and colleagues. In this study, tsetse flies were fed on rabbits to obtain anti-sera for subsequent screening of a cDNA expression library, resulting in the identification of tsetse antigen 5 (TAg5). In patients with allergic reactions to tsetse flies, $\operatorname{IgE}$ antibodies against $\mathrm{TAg} 5$ were detected, showing that this antigen is involved in the host-vector interface. Silencing of TAg5 in tsetse flies confirmed this observation as saliva from silenced flies displayed a reduced IgE binding potential. This study has contributed in confirming antigen-5 related proteins as functional allergens [223].

A standard PubMed search conducted with the terms Trypanosoma brucei and gene silencing or RNA interference indicate that 495 papers have been published using RNAi in T. brucei. We suggest 
reading some of the following reviews addressing new understanding of parasite biology and the identification of novel drug targets for parasite control [1,224-226].

\section{RNAi: From Basic Research to Control Strategies}

\subsection{RNAi Contributes to the Identification of Candidate Transgenes}

Transgenesis entails the transformation of vectors with transgenes that impair vector and/or pathogen development. This growing field of controlling vector-borne diseases is reviewed in [227-229]. Noteworthy is the contributions that RNAi-studies have made to the identification and evaluation of genes which are now used as transgenes to impact the mosquito vector-pathogen interactions (Table 3). Studies on transgenes affecting vector immune response genes such as Rel regulatory molecules (which affect the expression of numerous immune genes) and anti-microbial peptide genes such as defensins and cecropins, have pioneered this field [230]. With the growth in high-throughput screening studies, it is anticipated that the number of RNAi-discovered transgenes for vector-borne diseases will escalate within the next few years.

Table 3. Mosquito transgenes disrupting mosquito-pathogen interactions. Adapted from [227].

\begin{tabular}{|c|c|c|c|}
\hline Vector Species & Transgene & Pathogen(s) targeted & $\begin{array}{c}\text { Reference for RNAi of the } \\
\text { transgene }\end{array}$ \\
\hline \multicolumn{4}{|c|}{ Mosquito immune response genes } \\
\hline \multirow{4}{*}{ Ae. aegypti } & & Micrococcus luteus & \multirow{6}{*}[231-236]{} \\
\hline & Defensin A & Plasmodium & \\
\hline & & gallinaceum & \\
\hline & & Enterobacter cloacae & \\
\hline Ae geovinti & Cecropin A & Enterobacter cloacae & \\
\hline An. gambiae & & Plasmodium berghei & \\
\hline \multirow{4}{*}{ Ae. aegypti } & REL-genes & Plasmodium spp. & \\
\hline & (REL1 and REL2) & Bacillus subtilis & \\
\hline & & Escherichia coli & \\
\hline & & Others & \\
\hline An. stephensi & SM1 & Plasmodium berghei & [237] \\
\hline Ae. aegypti & $30 \mathrm{Ka} ; 30 \mathrm{~Kb}$ & Dengue Virus & [238] \\
\hline Ae. aegypti & Anti-DENV2 & Dengue Virus & {$[179,184]$} \\
\hline
\end{tabular}

\subsection{Paratransgenesis}

An additional strategy to reduce vector competence for disease transmission, involves genetic manipulation of natural endosymbionts of a particular vector species to produce molecules that impedes pathogen transmission or survival [239]. As described in this review, RNAi has already 
provided much insight into vector-pathogen interactions and paratrangenesis is already being used with success in vectors listed on VectorBase. This strategy was first described in Rhodnius prolixus, the Chagas disease vector, using its endosymbiont, Rhodococcus rhodnii. A gene encoding an antimicrobial peptide, cecropin A (which was evaluated using RNAi), was cloned into $R$. rhodnii that was stably expressed and released into the gut lumen, killing the disease causing pathogen $T$. cruzi with limited toxicity to the host tissues. Moreover, the transformed bacteria were stably maintained without the need for antibiotic selection and could be successfully transmitted to hosts with non-transformed endosymbionts due to the coprophagic habits of reduviids. In later studies, functionally active single chain antibody fragments ( $\mathrm{ScFv}$ ) were successfully expressed using a modified endosymbiotic Corynebacterium spiecies in the kissing bug, Triatoma infestans, as well as $R$. rhodnii in R. prolixus for control of T. cruzi transmission [239].

Other bacterial symbionts that have been successfully transformed and stably transmitted include Sodalis glossinidius (from Glossina sp.) and Asia sp. (from Anopheles spp.) [240,241]. Transformed Asia was also shown to be paternally transmitted in An. stephensi, providing the possibility of using non-hematophagous mosquitoes to spread modified endosymbionts for pathogen transmission control [242]. A reduction in vector competence may also be achieved by using genetically modified densovirusses in mosquitoes. In this regard, transmission of modified virus has been reported for Ae. aegypti and A gambiae, respectively [243,244]. To date, a number of endosymbionts have been identified may be used in paratransgenic control of insect-borne diseases from triatomine, tsetse fly and mosquito vectors [227]. However, few species have been successfully modified and shown to be stably transmitted to non-transformed individuals and their resultant progeny. In theory, genetically modified endosymbionts may not only provide researches with an additional tool for fighting disease but it can also deliver proteins and enzymes that test functional genetic hypotheses formulated from RNAi studies.

\subsection{RNAi Together with Integrated High-Throughput Technologies Pave the Way for the Future in Combatting Pathogen and Their Vectors}

The discovery of RNAi, for which Andrew Fire and Craig C. Mello were awarded the Nobel Prize in Physiology or Medicine in 2006, has once more demonstrated the importance of basic science in understanding molecular and physiological mechanisms. With this revelation the door was opened to the development of powerful approaches for investigation of functional genomics in a wide array of organisms, including those of importance in human and animal health. In the post genomic era, with a vast array of sequence information, RNAi provides a method to functionally annotate and subsequently validate the expanding spectrum of putative vaccine and drug targets, this is especially evident in the fields of tick and mosquito research.

RNAi in combination with recently developed technologies, such as high-throughput screening provides a platform to investigate proteins of vital importance in pathogen survival, transmission and the pathogen-vector-host interface. RNAi together with technologies such as deep sequencing revolutionized pathogen and vector research by enabling the comprehensive and refined annotation of the genomes of these organisms, leading to better knowledge of their RNA, proteins and metabolite 
derivatives. This finally provides an integrated systematic molecular biological approach for new optimized control strategies against these medical and veterinary important organisms [245].

Together with genomic data and RNAi integrated technologies basic biological questions regarding vectors and their pathogens are in the process of being elucidated. High-throughput sequencing provides an invaluable tool to furthermore investigate the full repertoire of RNAi machinery, to identify essential components of the pathway and even perhaps to reveal new classes of small silencing RNAs. This knowledge will allow for fundamental improvements in RNAi efficiency in RNAi-positive organisms and furthermore permit applied research, as the RNAi machinery can be reconstructed in organisms lacking the RNAi pathway, since the proof of concept has been confirmed in Saccharomyces cerevisiae [246].

\section{Acknowledgements}

We are most grateful to Willem Andries van Zyl for critical reading of this manuscript.

\section{References}

1. Kolev, N.G.; Tschudi, C.; Ullu, E. RNA interference in protozoan parasites: achievements and challenges. Eukaryot Cell. 2011, 10, 1156-1163.

2. Sutherst, R.W. Global change and human vulnerability to vector-borne diseases. Clin. Microbiol. Rev. 2004, 17, 136-173.

3. Rogers, D.J.; Randolph, S.E. Climate change and vector-borne diseases. Adv. Parasitol. 2006, 62, 345-381.

4. Severson, D.W.; Behura, S.K. Mosquito genomics: progress and challenges. Annu. Rev. Entomol. 2012, 57, 143-166.

5. Gadelha, C.; Holden, J.M.; Allison, H.C.; Field, M.C. Specializations in a successful parasite: what makes the bloodstream-form African trypanosome so deadly? Mol. Biochem. Parasitol. 2011, 179, 51-58.

6. Suarez, C.E.; Noh, S. Emerging perspectives in the research of bovine babesiosis and anaplasmosis. Vet. Parasitol. 2011, 180, 109-125.

7. Schuijt, T.; Hovius, J.W.; van der Poll, T.; van Dam, A.P.; Fikrig, E. Lyme borreliosis vaccination: the facts, the challenge, the future. Trends. Parasitol. 2011, 40-47.

8. Mito, T.; Nakamura, T.; Bando, T.; Hideyo, O.; Sumihare, N. The advent of RNA interference in entomology. Entomol. Sci. 2011, 14, 1-8.

9. Lawson, D.; Arensburger, P.; Atkinson, P.; Besansky, N.J.; Bruggner, R.V.; Butler, R.; Campbell, K.S.; Christophides, G.K.; Christley, S.; Dialynas, E.; et al. VectorBase: A home for invertebrate vectors of human pathogens. Nucleic Acids Res. 2007, 35, D503-505.

10. Topalis, P.; Dialynas, E.; Mitraka, E.; Deligianni, E.; Siden-Kiamos, I.; Louis, C. A set of ontologies to drive tools for the control of vector-borne diseases. J. Biomed. Inform. 2011, 44, 42-47.

11. Mills, J.N.; Gage, K.L.; Khan, A.S. Potential influence of climate change on vector-borne and zoonotic diseases: a review and proposed research plan. Environ. Health Perspect 2010, 118, 1507-1514. 
12. Lawson, D.; Arensburger, P.; Atkinson, P.; Besansky, N.J.; Bruggner, R.V.; Butler, R.; Campbell, K.S.; Christophides, G.K.; Christley, S.; Dialynas, E.; et al. VectorBase: a data resource for invertebrate vector genomics. Nucleic Acids Res. 2009, 37, D583-587.

13. Liu, Q.; Paroo, Z. Biochemical principles of small RNA pathways. Annu Rev. Biochem. 2010, 79, 295-319.

14. Hammond, S.M. Dicing and slicing: the core machinery of the RNA interference pathway. FEBS Lett. 2005, 579, 5822-5829.

15. Walshe, D.P.; Lehane, S.M.; Lehane, M.J.; Haines, L.R. Prolonged gene knockdown in the tsetse fly Glossina by feeding double stranded RNA. Insect Mol. Biol. 2009, 18, 11-19.

16. Benoit, J.B.; Yang, G.; Krause, T.B.; Patrick, K.R.; Aksoy, S.; Attardo, G.M. Lipophorin acts as a shuttle of lipids to the milk gland during tsetse fly pregnancy. J. Insect Physiol. 2011, 57, $1553-1561$.

17. Caljon, G.; De Ridder, K.; De Baetselier, P.; Coosemans, M.; Van Den Abbeele, J. Identification of a tsetse fly salivary protein with dual inhibitory action on human platelet aggregation. PLoS One 2010, 5, e9671.

18. Durand-Dubief, M.; Bastin, P. TbAGO1, an argonaute protein required for RNA interference, is involved in mitosis and chromosome segregation in Trypanosoma brucei. BMC Biol. 2003, 1, 2.

19. Shi, H.; Djikeng, A.; Tschudi, C.; Ullu, E. Argonaute protein in the early divergent eukaryote Trypanosoma brucei: control of small interfering RNA accumulation and retroposon transcript abundance. Mol. Cell Biol. 2004, 24, 420-427.

20. Shi, H.; Tschudi, C.; Ullu, E. An unusual Dicer-like1 protein fuels the RNA interference pathway in Trypanosoma brucei. RNA 2006, 12, 2063-2072.

21. Patrick, K.L.; Shi, H.; Kolev, N.G.; Ersfeld, K.; Tschudi, C.; Ullu, E. Distinct and overlapping roles for two Dicer-like proteins in the RNA interference pathways of the ancient eukaryote Trypanosoma brucei. Proc. Natl. Acad. Sci. USA 2009, 106, 17933-17938.

22. Barnes, R.L.; Shi, H.; Kolev, N.G.; Tschudi, C.; Ullu, E. Comparative genomics reveals two novel RNAi factors in Trypanosoma brucei and provides insight into the core machinery. PLoS Pathog 2012, 8, e1002678.

23. Araujo, R.N.; Santos, A.; Pinto, F.S.; Gontijo, N.F.; Lehane, M.J.; Pereira, M.H. RNA interference of the salivary gland nitrophorin 2 in the triatomine bug Rhodnius prolixus (Hemiptera: Reduviidae) by dsRNA ingestion or injection. Insect Biochem. Mol. Biol. 2006, 36, 683-693.

24. Paim, R.M.; Araujo, R.N.; Soares, A.C.; Lemos, L.C.; Tanaka, A.S.; Gontijo, N.F.; Lehane, M.J.; Pereira, M.H. Influence of the intestinal anticoagulant in the feeding performance of triatomine bugs (Hemiptera; Reduviidae). Int. J. Parasitol. 2011, 41, 765-773.

25. Garcia Silva, M.R.; Tosar, J.P.; Frugier, M.; Pantano, S.; Bonilla, B.; Esteban, L.; Serra, E.; Rovira, C.; Robello, C.; Cayota, A. Cloning, characterization and subcellular localization of a Trypanosoma cruzi argonaute protein defining a new subfamily distinctive of trypanosomatids. Gene 2010, 15, 26-35.

26. Kurscheid, S.; Lew-Tabor, A.E.; Rodriguez Valle, M.; Bruyeres, A.G.; Doogan, V.J.; Munderloh, U.G.; Guerrero, F.D.; Barrero, R.A.; Bellgard, M.I. Evidence of a tick RNAi 
pathway by comparative genomics and reverse genetics screen of targets with known loss-offunction phenotypes in Drosophila. BMC Mol. Biol. 2009, 10, 26.

27. Campbell, C.L.; Black, W.C. t.; Hess, A.M.; Foy, B.D. Comparative genomics of small RNA regulatory pathway components in vector mosquitoes. BMC Genomics 2008, 9, 425.

28. Xue, X.; Zhang, Q.; Huang, Y.; Feng, L.; Pan, W. No miRNA were found in Plasmodium and the ones identified in erythrocytes could not be correlated with infection. Malar J. 2008, 7, 47.

29. Baum, J.; Papenfuss, A.T.; Mair, G.R.; Janse, C.J.; Vlachou, D.; Waters, A.P.; Cowman, A.F.; Crabb, B.S.; de Koning-Ward, T.F. Molecular genetics and comparative genomics reveal RNAi is not functional in malaria parasites. Nucleic Acids. Res. 2009, 37, 3788-3798.

30. Tomari, Y.; Zamore, P.D. Perspective: machines for RNAi. Genes Dev. 2005, 19, 517-529.

31. Sashital, D.; Doudna, J.A. Structural Insights into RNA Interference. Curr. Opin. Struct. Biol. 2010, 20, 90-97.

32. Fire, A.; Xu, S.; Montgomery, M.K.; Kostas, S.A.; Driver, S.E.; Mello, C.C. Potent and specific genetic interference by double-stranded RNA in Caenorhabditis elegans. Nature 1998, 391, 806-811.

33. Huvenne, H.; Smagghe, G. Mechanisms of dsRNA uptake in insects and potential of RNAi for pest control: a review. J. Insect Physiol 2010, 56, 227-235.

34. Winston, W.M.; Molodowitch, C.; Hunter, C.P. Systemic RNAi in C. elegans requires the putative transmembrane protein SID-1. Science 2002, 295, 2456-2459.

35. Wu-yang, Z.; Guo-dong, L. Research on basis of reverse genetics system of a Sindbis-like virus XJ-160. Virol. J. 2011, 8, 519.

36. Jose, A.M.; Smith, J.J.; Hunter, C.P. Export of RNA silencing from C. elegans tissues does not require the RNA channel SID-1. Proc. Natl. Acad. Sci. USA 2009, 106, 2283-2288.

37. Calixto, A.; Chelur, D.; Topalidou, I.; Chen, X.; Chalfie, M. Enhanced neuronal RNAi in C. elegans using SID-1. Nature Meth. 2010, 7, 554-559.

38. Tomoyasu, Y.; Miller, S.C.; Tomita, S.; Schoppmeier, M.; Grossman, D.; Bucher, G. Exploring systemic RNA interference in insects: A genome-wide survey for RNAi genes in Tribolium. Genome Biol. 2008, 9, R10.

39. Ulvila, J.; Parikka, M.; Kleino, A.; Sormunen, R.; Ezekowitz, R.A.; Kocks, C.; Ramet, M. Double-stranded RNA is internalized by scavenger receptor-mediated endocytosis in Drosophila S2 cells. J. Biol. Chem. 2006, 281, 14370-14375.

40. Saleh, M.C.; van Rij, R.P.; Hekele, A.; Gillis, A.; Foley, E.; O'Farrell, P.H.; Andino, R. The endocytic pathway mediates cell entry of dsRNA to induce RNAi silencing. Nat. Cell. Biol. 2006, 8, 793-802.

41. McManus, M.T.; Sharp, P.A. Gene silencing in mammals by small interfering RNAs. Nat. Rev. Genet. 2002, 3, 737-747.

42. Agrawal, N.; Dasaradhi, P.V.; Mohmmed, A.; Malhotra, P.; Bhatnagar, R.K.; Mukherjee, S.K. RNA interference: biology, mechanism, and applications. Microbiol. Mol. Biol. Rev. 2003, 67, $657-685$.

43. Elbashir, S.M.; Lendeckel, W.; Tuschl, T. RNA interference is mediated by 21- and 22nucleotide RNAs. Genes Dev. 2001, 15, 188-200. 
44. Zamore, P.D.; Tuschl, T.; Sharp, P.A.; Bartel, D.P. RNAi: double-stranded RNA directs the ATP-dependent cleavage of mRNA at 21 to 23 nucleotide intervals. Cell 2000, 101, 25-33.

45. Bernstein, E.; Caudy, A.A.; Hammond, S.M.; Hannon, G.J. Role for a bidentate ribonuclease in the initiation step of RNA interference. Nature 2001, 409, 363-366.

46. Bernstein, E.; Denli, A.M.; Hannon, G.J. The rest is silence. RNA 2001, 7, 1509-1521.

47. Zhang, J.; Hua, Z.C. Targeted gene silencing by small interfering RNA-based knock-down technology. Curr. Pharm. Biotechnol. 2004, 5, 1-7.

48. Yan, K.S.; Yan, S.; Farooq, A.; Han, A.; Zeng, L.; Zhou, M.M. Structure and conserved RNA binding of the PAZ domain. Nature 2003, 426, 468-474.

49. Song, J.J.; Liu, J.; Tolia, N.H.; Schneiderman, J.; Smith, S.K.; Martienssen, R.A.; Hannon, G.J.; Joshua-Tor, L. The crystal structure of the Argonaute2 PAZ domain reveals an RNA binding motif in RNAi effector complexes. Nat. Struct. Biol. 2003, 10, 1026-1032.

50. Ma, J.B.; Ye, K.; Patel, D.J. Structural basis for overhang-specific small interfering RNA recognition by the PAZ domain. Nature 2004, 429, 318-322.

51. Zhang, H.; Kolb, F.A.; Brondani, V.; Billy, E.; Filipowicz, W. Human Dicer preferentially cleaves dsRNAs at their termini without a requirement for ATP. EMBO J. 2002, 21, 5875-5885.

52. Macrae, I.J.; Li, F.; Zhou, K.; Cande, W.Z.; Doudna, J.A. Structure of Dicer and mechanistic implications for RNAi. Cold Spring Harb. Symp. Quant. Biol. 2006, 71, 73-80.

53. Macrae, I.J.; Zhou, K.; Li, F.; Repic, A.; Brooks, A.N.; Cande, W.Z.; Adams, P.D.; Doudna, J.A. Structural basis for double-stranded RNA processing by Dicer. Science 2006, 311, 195-198.

54. MacRae, I.J.; Zhou, K.; Doudna, J.A. Structural determinants of RNA recognition and cleavage by Dicer. Nat. Struct. Mol. Biol. 2007, 14, 934-940.

55. Lau, P.; Potter, C.S.; Carragher, B.; MacRae2, I.J. Structure of the Human Dicer-TRBP Complex by Electron Microscopy. Structure 2009, 14, 1326-1332.

56. Lee, Y.; Hur, I.; Park, S.Y.; Kim, Y.K.; Suh, M.R.; Kim, V.N. The role of PACT in the RNA silencing pathway. EMBO J. 2006, 25, 522-532.

57. Ma, E.; MacRae, I.J.; Kirsch, J.F.; Doudna, J.A. Autoinhibition of human dicer by its internal helicase domain. J. Mol. Biol. 2008, 380, 237-243.

58. Dlakic, M. DUF283 domain of Dicer proteins has a double-stranded RNA-binding fold. Bioinformatics 2006, 22, 2711-2714.

59. Sasaki, T.; Shimizu, N. Evolutionary conservation of a unique amino acid sequence in human DICER protein essential for binding to Argonaute family proteins. Gene 2007, 396, 312-320.

60. Provost, P.; Dishart, D.; Doucet, J.; Frendewey, D.; Samuelsson, B.; Radmark, O. Ribonuclease activity and RNA binding of recombinant human Dicer. EMBO J. 2002, 21, 5864-5874.

61. Kawamata, T.; Tomari, Y. Making RISC. Trends Biochem Sci 2010, 35, 368-376.

62. Jaskiewicz, L.; Filipowicz, W. Role of Dicer in posttranscriptional RNA silencing. Curr. Top. Microbiol. Immunol. 2008, 320, 77-97.

63. Wang, H.; Noland, C.; Siridechadilok, B.; Taylor, D.W.; Ma, E.; Felderer, K.; Doudna, J.A.; Nogales, E. Structural insights into RNA processing by the human RISC-loading complex. Nat. Struct. Mol. Biol. 2009, 16, 1148-1153. 
64. Tomari, Y.; Du, T.; Haley, B.; Schwarz, D.S.; Bennett, R.; Cook, H.A.; Koppetsch, B.S.; Theurkauf, W.E.; Zamore, P.D. RISC assembly defects in the Drosophila RNAi mutant armitage. Cell 2004, 116, 831-841.

65. Tomari, Y.; Matranga, C.; Haley, B.; Martinez, N.; Zamore, P.D. A protein sensor for siRNA asymmetry. Science 2004, 306, 1377-1380.

66. Schwarz, D.S.; Hutvagner, G.; Du, T.; Xu, Z.; Aronin, N.; Zamore, P.D. Asymmetry in the assembly of the RNAi enzyme complex. Cell 2003, 115, 199-208.

67. Khvorova, A.; Reynolds, A.; Jayasena, S.D. Functional siRNAs and miRNAs exhibit strand bias. Cell 2003, 115, 209-216.

68. Pham, J.W.; Pellino, J.L.; Lee, Y.S.; Carthew, R.W.; Sontheimer, E.J. A Dicer-2-dependent 80s complex cleaves targeted mRNAs during RNAi in Drosophila. Cell 2004, 117, 83-94.

69. Pham, J.W.; Sontheimer, E.J. The Making of an siRNA. Mol. Cell 2004, 15, 163-164.

70. Rand, T.A.; Petersen, S.; Du, F.; Wang, X. Argonaute2 Cleaves the Anti-Guide Strand of siRNA during RISC Activation. Cell 2005, 123, 621-629.

71. Matranga, C.; Tomari, Y.; Shin, C.; Bartel, D.P.; Zamore, P.D. Passenger-strand cleavage facilitates assembly of siRNA into Ago2-containing RNAi enzyme complexes. Cell 2005, 123, 607-620.

72. van den Berg, A.; Mols, J.; Han, J. RISC-Target Interaction: Cleavage and Translational Suppression. Biochimica et Biophysica 2008 1779, 668-677.

73. Hutvagner, G.; Simar, M.J. Argonaute proteins: key player in RNA silencing. Nat. Rev. Mol. Biol. 2008, 9, 22-31.

74. Hammond, S.M.; Boettcher, S.; Caudy, A.A.; Kobayashi, R.; Hannon, G.J. Argonaute2, a link between genetic and biochemical analyses of RNAi. Science 2001, 293, 1146-1150.

75. Song, J.J.; Smith, S.K.; Hannon, G.J.; Joshua-Tor, L. Crystal structure of Argonuate and its implication for RISC slicer activity. Science 2004, 305, 1434-1437.

76. Sasaki, T.; Shiohama, A.; Minoshima, S.; Shimizu, N. Identification of eight members of the Argonaute family in the human genome. Genomics 2003, 82, 323-330.

77. Yigit, E.; Batista, P.J.; Bei, Y.; Pang, K.M.; Chen, C.C.; Tolia, N.H.; Joshua-Tor, L.; Mitani, S.; Simard, M.J.; Mello, C.C. Analysis of the C. elegans Argonaute family reveals that distinct Argonautes act sequentially during RNAi. Cell 2006, 127, 747-757.

78. Caudy, A.A.; Ketting, R.F.; Hammond, S.M.; Denli, A.M.; Bathoorn, A.M.P.; Tops, B.B.J.; Silva, J.M.; Myers, M.M.; Hannon, G.J.; Plasterk, R.H.A. A micrococcal nuclease homologue in RNAi effector complexes. Nature 2003, 425, 411-414.

79. Caudy, A.A.; Myers, M.; Hannon, G.J.; Hammond, S.M. Fragile X-related protein and VIG associate with the RNA interference machinery. Genes Dev. 2002, 16, 2491-2496.

80. Hall, T.M. Structure and function of argonaute proteins. Structure 2005, 13, 1403-1408.

81. Ma, J.B.; Yuan, Y.R.; Meister, G.; Pei, Y.; Tuschl, T.; Patel, D.J. Structural basis for 5'-endspecific recognition of guide RNA by the A. fulgidus Piwi protein. Nature 2005, 434, 666-670.

82. Parker, J.S.; Roe, S.M.; Barford, D. Crystal structure of a PIWI protein suggests mechanisms for siRNA recognition and slicer activity. EMBO J. 2004, 23, 4727-4737.

83. Nykanen, A.; Haley, B.; Zamore, P.D. ATP Requirements and Small Interfering RNA Structure in the RNA Interference Pathway. Cell 2001, 107, 309-321. 
84. Haley, B.; Zamore, P.D. Kinetic analysis of the RNAi enzyme complex. Nat. Struct. Mol. Biol. 2004, 11, 599-606.

85. Zamore, P.D.; Haley, B. Ribo-gnome: The big world of small RNAs. Science 2005, 309, $1519-1524$.

86. Cerutti, H. RNA interference: Traveling in the cell and gaining functions? Trends Genet. 2003, 19, 39-46.

87. Karim, S.; Ramakrishnan, V.J.; Tucker, J.S.; Essenberg, R.C.; Sauer, J.R. Amblyomma americanum salivary glands:double-stranded RNA-mediated gene silencing of synaptobrevin homologue and inhibition of PGE2 stimulated protein secretion. Insect Biochem. Mol. Biol. 2004, 34, 407-413.

88. Nijhof, A.M.; Taoufik, A.; de la Fuente, J.; Kocan, K.M.; de Vries, E.; Jongejan, F. Gene silencing of the tick protective antigens, Bm86, Bm91 and subolesin, in the one-host tick Boophilus microplus by RNA interference. Int. J. Parasitol. 2007, 37, 653-662.

89. Soares, C.A.; Lima, C.M.; Dolan, M.C.; Piesman, J.; Beard, C.B.; Zeidner, N.S. Capillary feeding of specific dsRNA induces silencing of the isac gene in nymphal Ixodes scapularis ticks. Insect Mol. Biol. 2005, 14, 443-452.

90. Barnard, A.-C.; Nijhof, A.M.; Gaspar, A.R.; Neitz, A.W.; Jongejan, F.; Maritz-Olivier, C. Expression profiling, gene silencing and transcriptional networking of metzincin metalloproteases in the cattle tick, Rhipicephalus (Boophilus) microplus. Vet. Parasitol. 2012, 186, 403-414.

91. Tijsterman, M.; May, R.C.; Simmer, F.; Okihara, K.L.; Plasterk, R.H. Genes required for systemic RNA interference in Caenorhabditis elegans. Curr. Biol. 2004, 14, 111-116.

92. Sijen, T.; Fleenor, J.; Simmer, F.; Thijssen, K.L.; Parrish, S.; Timmons, L.; Plasterk, R.H.A.; Fire, A. On the role of RNA amplification in dsRNA-triggered gene silencing. Cell 2001, 107, 465-476.

93. Aung, K.M.; Boldbaatar, D.; Umemiya-Shirafuji, R.; Liao, M.; Xuenan, X.; Suzuki, H.; Galay, R.L.; Tanaka, T.; Fujisaki, K. Scavenger receptor mediates systemic RNA interference in ticks. PLoS One 2011, 6, e28407.

94. Smardon, A.; Spoerke, J.M.; Stacey, S.C.; Klein, M.E.; Mackin, N.; Maine, E.M. EGO-1 is related to RNA-directed RNA polymerase and functions in germ-line development and RNA interference in C. elegans. Curr. Biol. 2000, 10, 169-178.

95. Buchon, N.; Vaury, C. RNAi: A defensive RNA-silencing against viruses and transposable elements. Heredity 2006, 96, 196-202.

96. Jongejan, F.; Uilenberg, G. The global importance of ticks. Parasitology 2004, 129, S3-S14.

97. Guerrero, F.D.; Nene, V.M.; George, J.E.; Barker, S.C.; Willadsen, P. Sequencing a new target genome: The Boophilus microplus (Acari: Ixodidae) genome project. J. Med. Entomol. 2006, 43, 9-16.

98. Bellgard, M.I.; Moolhuijzen, P.M.; Guerrero, F.D.; Schibeci, D.; Rodriguez-Valle, M.; Peterson, D.G.; Dowd, S.E.; Barrero, R.; Hunter, A.; Miller, R.J.; et al. CattleTickBase: An integrated Internet-based bioinformatics resource for Rhipicephalus (Boophilus) microplus. Int. J. Parasitol. 2012, 42, 161-169. 
99. Pagel Van Zee, J.; Geraci, N.S.; Guerrero, F.D.; Wikel, S.K.; Stuart, J.J.; Nene, V.M.; Hill, C.A. Tick genomics: the Ixodes genome project and beyond. Int. J. Parasitol. 2007, 37, 1297-1305.

100. Aljamali, M.N.; Sauer, J.R.; Essenberg, R.C. RNA interference: applicability in tick research. Exp. Appl. Acarol. 2002, 28, 89-96.

101. de la Fuente, J.; Almazan, C.; Blas-Machado, U.; Naranjo, V.; Mangold, A.J.; Blouin, E.F.; Gortazar, C.; Kocan, K.M. The tick protective antigen, 4D8, is a conserved protein involved in modulation of tick blood ingestion and reproduction. Vaccine 2006, 24, 4082-4095.

102. Miyoshi, T.; Tsuji, N.; Islam, M.K.; Kamio, T.; Fujisaki, K. Gene silencing of a cubilin-related serine proteinase from the hard tick Haemaphysalis longicornis by RNA interference. $J$. Vet. Med. Sci. 2004, 66, 1471-1473.

103. Manzano-Roman, R.; Diaz-Martin, V.; Oleaga, A.; Siles-Lucas, M.; Perez-Sanchez, R. Subolesin/akirin orthologs from Ornithodoros spp. soft ticks: Cloning, RNAi gene silencing and protective effect of the recombinant proteins. Vet. Parasitol. 2012, 185, 248-259.

104. Grbic, M.; Van Leeuwen, T.; Clark, R.M.; Rombauts, S.; Rouze, P.; Grbic, V.; Osborne, E.J.; Dermauw, W.; Ngoc, P.C.; Ortego, F.; et al. The genome of Tetranychus urticae reveals herbivorous pest adaptations. Nature 2011, 479, 487-492.

105. Campbell, E.M.; Budge, G.E.; Bowman, A.S. Gene-knockdown in the honey bee mite Varroa destructor by a non-invasive approach: studies on a glutathione S-transferase. Parasit Vectors 2010, 3, 73.

106. Khila, A.; Grbic, M. Gene silencing in the spider mite Tetranychus urticae: dsRNA and siRNA parental silencing of the Distal-less gene. Dev. Genes Evol. 2007, 217, 241-251.

107. Ceraul, S.M.; Chung, A.; Sears, K.T.; Popov, V.L.; Beier-Sexton, M.; Rahman, M.S.; Azad, A.F. A Kunitz protease inhibitor from Dermacentor variabilis, a vector for spotted fever group rickettsiae, limits Rickettsia montanensis invasion. Infect. Immun. 2011, 79, 321-329.

108. Narasimhan, S.; Sukumaran, B.; Bozdogan, U.; Thomas, V.; Liang, X.; DePonte, K.; Marcantonio, N.; Koski, R.A.; Anderson, J.F.; Kantor, F.; et al. A tick antioxidant facilitates the Lyme disease agent's successful migration from the mammalian host to the arthropod vector. Cell Host Microbe 2007, 2, 7-18.

109. Pedra, J.H.; Narasimhan, S.; Rendic, D.; DePonte, K.; Bell-Sakyi, L.; Wilson, I.B.; Fikrig, E. Fucosylation enhances colonization of ticks by Anaplasma phagocytophilum. Cell Microbiol. 2010, 12, 1222-1234.

110. Seinen, E.; Burgerhof, J.G.; Jansen, R.C.; Sibon, O.C. RNAi experiments in D. melanogaster: solutions to the overlooked problem of off-targets shared by independent dsRNAs. PLoS One 2010, 5, e13119.

111. Sigoillot, F.D.; Lyman, S.; Huckins, J.F.; Adamson, B.; Chung, E.; Quattrochi, B.; King, R.W. A bioinformatics method identifies prominent off-targeted transcripts in RNAi screens. Nat. Meth. 2012, 9, 363-366.

112. Lew-Tabor, A.E.; Kurscheid, S.; Barrero, R.; Gondro, C.; Moolhuijzen, P.M.; Rodriguez Valle, M.; Morgan, J.A.; Covacin, C.; Bellgard, M.I. Gene expression evidence for off-target effects caused by RNA interference-mediated gene silencing of Ubiquitin-63E in the cattle tick Rhipicephalus microplus. Int. J. Parasitol. 2011, 41, 1001-1014. 
113. Campbell, E.M.; Burdin, M.; Hoppler, S.; Bowman, A.S. Role of an aquaporin in the sheep tick Ixodes ricinus: assessment as a potential control target. Int. J. Parasitol. 2010, 40, 15-23.

114. Buresova, V.; Hajdusek, O.; Franta, Z.; Sojka, D.; Kopacek, P. IrAM-An alpha2-macroglobulin from the hard tick Ixodes ricinus: characterization and function in phagocytosis of a potential pathogen Chryseobacterium indologenes. Dev. Comp. Immunol. 2009, 33, 489-498.

115. Narasimhan, S.; Montgomery, R.R.; DePonte, K.; Tschudi, C.; Marcantonio, N.; Anderson, J.F.; Sauer, J.R.; Cappello, M.; Kantor, F.S.; Fikrig, E. Disruption of Ixodes scapularis anticoagulation by using RNA interference. Proc. Natl. Acad. Sci. USA 2004, 101, 1141-1146.

116. Umemiya-Shirafuji, R.; Tanaka, T.; Boldbaatar, D.; Fujisaki, K. Akt is an essential player in regulating cell/organ growth at the adult stage in the hard tick Haemaphysalis longicornis. Insect Biochem. Mol. Biol. 2012, 42, 164-173.

117. Alim, M.A.; Tsuji, N.; Miyoshi, T.; Islam, M.K.; Hatta, T.; Fujisaki, K. Legumains from the hard tick Haemaphysalis longicornis play modulatory roles in blood feeding and gut cellular remodelling and impact on embryogenesis. Int. J. Parasitol. 2009, 39, 97-107.

118. Kocan, K.M.; Manzano-Roman, R.; de la Fuente, J. Transovarial silencing of the subolesin gene in three-host ixodid tick species after injection of replete females with subolesin dsRNA. Parasitol. Res. 2007, 100, 1411-1415.

119. Merino, O.; Almazan, C.; Canales, M.; Villar, M.; Moreno-Cid, J.A.; Estrada-Pena, A.; Kocan, K.M.; de la Fuente, J. Control of Rhipicephalus (Boophilus) microplus infestations by the combination of subolesin vaccination and tick autocidal control after subolesin gene knockdown in ticks fed on cattle. Vaccine 2011, 29, 2248-2254.

120. Garcia, S.; Billecocq, A.; Crance, J.M.; Munderloh, U.; Garin, D.; Bouloy, M. Nairovirus RNA sequences expressed by a Semliki Forest virus replicon induce RNA interference in tick cells. J. Virol. 2005, 79, 8942-8947.

121. Barry, G.; Alberdi, P.; Schnettler, E.; Weisheit, S.; Kohl, A.; Fazakerley, J.K.; Bell-Sakyi, L. Gene silencing in tick cell lines using small interfering or long double-stranded RNA. Exp. Appl. Acarol. 2012, in press.

122. Karim, S.; Kenny, B.; Troiano, E.; Mather, T.N. RNAi-mediated gene silencing in tick synganglia: a proof of concept study. BMC Biotechnol. 2008, 8, 30.

123. Aljamali, M.N.; Bior, A.D.; Sauer, J.R.; Essenberg, R.C. RNA interference in ticks: a study using histamine binding protein dsRNA in the female tick Amblyomma americanum. Insect Mol. Biol. 2003, 12, 299-305.

124. Gong, H.; Umemiya, R.; Zhou, J.; Liao, M.; Zhang, H.; Jia, H.; Nishikawa, Y.; Xuan, X.; Fujisaki, K. Blocking the secretion of saliva by silencing the HlYkt6 gene in the tick Haemaphysalis longicornis. Insect Biochem. Mol. Biol. 2009, 39, 372-381.

125. Karim, S.; Troiano, E.; Mather, T.N. Functional genomics tool: gene silencing in Ixodes scapularis eggs and nymphs by electroporated dsRNA. BMC Biotechnol. 2010, 10, 1.

126. Beaufays, J.; Adam, B.; Menten-Dedoyart, C.; Fievez, L.; Grosjean, A.; Decrem, Y.; Prevot, P.P.; Santini, S.; Brasseur, R.; Brossard, M.; et al. Ir-LBP, an Ixodes ricinus tick salivary LTB4binding lipocalin, interferes with host neutrophil function. PLoS One 2008, 3, e3987. 
127. Dai, J.; Narasimhan, S.; Zhang, L.; Liu, L.; Wang, P.; Fikrig, E. Tick histamine release factor is critical for Ixodes scapularis engorgement and transmission of the lyme disease agent. PLoS Pathog. 2010, 6, e1001205.

128. Decrem, Y.; Mariller, M.; Lahaye, K.; Blasioli, V.; Beaufays, J.; Zouaoui Boudjeltia, K.; Vanhaeverbeek, M.; Cerutti, M.; Brossard, M.; Vanhamme, L.; et al. The impact of gene knock-down and vaccination against salivary metalloproteases on blood feeding and egg laying by Ixodes ricinus. Int. J. Parasitol. 2008, 38, 549-560.

129. Gao, X.; Shi, L.; Zhou, Y.; Cao, J.; Zhang, H.; Zhou, J. Characterization of the anticoagulant protein Rhipilin-1 from the Rhipicephalus haemaphysaloides tick. J. Insect Physiol. 2011, 57, 339-343.

130. Guo, X.; Booth, C.J.; Paley, M.A.; Wang, X.; DePonte, K.; Fikrig, E.; Narasimhan, S.; Montgomery, R.R. Inhibition of neutrophil function by two tick salivary proteins. Infect. Immun. 2009, 77, 2320-2329.

131. Karim, S.; Ramakrishnan, V.G.; Tucker, J.S.; Essenberg, R.C.; Sauer, J.R. Amblyomma americanum salivary gland homolog of $\mathrm{nSec} 1$ is essential for saliva protein secretion. Biochem. Biophys Res. Commun. 2004, 324, 1256-1263.

132. Franta, Z.; Sojka, D.; Frantova, H.; Dvorak, J.; Horn, M.; Srba, J.; Talacko, P.; Mares, M.; Schneider, E.; Craik, C.S.; et al. IrCL1 - the haemoglobinolytic cathepsin L of the hard tick, Ixodes ricinus. Int. J. Parasitol. 2011, 41, 1253-1262.

133. Miyoshi, T.; Tsuji, N.; Islam, M.K.; Alim, M.A.; Hatta, T.; Huang, X.; Fujisaki, K. A set of serine proteinase paralogs are required for blood-digestion in the ixodid tick Haemaphysalis longicornis. Parasitol. Int. 2008, 57, 499-505.

134. Hajdusek, O.; Sojka, D.; Kopacek, P.; Buresova, V.; Franta, Z.; Sauman, I.; Winzerling, J.; Grubhoffer, L. Knockdown of proteins involved in iron metabolism limits tick reproduction and development. Proc. Natl. Acad. Sci. USA 2009, 106, 1033-1038.

135. Guo, X.; Reuben Kaufman, W. Identification of two genes essential for sperm development in the male tick Amblyomma hebraeum Koch (Acari: Ixodidae). Insect Biochem. Mol. Biol. 2008, $38,721-729$.

136. Smith, A.; Guo, X.; de la Fuente, J.; Naranjo, V.; Kocan, K.M.; Kaufman, W.R. The impact of RNA interference of the subolesin and voraxin genes in male Amblyomma hebraeum (Acari: Ixodidae) on female engorgement and oviposition. Exp. Appl. Acarol. 2009, 47, 71-86.

137. Buresova, V.; Hajdusek, O.; Franta, Z.; Loosova, G.; Grunclova, L.; Levashina, E.A.; Kopacek, P. Functional genomics of tick thioester-containing proteins reveal the ancient origin of the complement system. J. Innate Immun. 2011, 3, 623-630.

138. de la Fuente, J.; Almazan, C.; Blouin, E.F.; Naranjo, V.; Kocan, K.M. RNA interference screening in ticks for identification of protective antigens. Parasitol. Res. 2005, 96, 137-141.

139. de la Fuente, J.; Manzano-Roman, R.; Naranjo, V.; Kocan, K.M.; Zivkovic, Z.; Blouin, E.F.; Canales, M.; Almazan, C.; Galindo, R.C.; Step, D.L.; et al. Identification of protective antigens by RNA interference for control of the lone star tick, Amblyomma americanum. Vaccine 2010, 28, 1786-1795.

140. de la Fuente, J.; Moreno-Cid, J.A.; Canales, M.; Villar, M.; de la Lastra, J.M.; Kocan, K.M.; Galindo, R.C.; Almazan, C.; Blouin, E.F. Targeting arthropod subolesin/akirin for the 
development of a universal vaccine for control of vector infestations and pathogen transmission. Vet. Parasitol. 2011, 181, 17-22.

141. de la Fuente, J.; Almazan, C.; Naranjo, V.; Blouin, E.F.; Meyer, J.M.; Kocan, K.M. Autocidal control of ticks by silencing of a single gene by RNA interference. Biochem. Biophys Res. Commun. 2006, 344, 332-338.

142. de la Fuente, J.; Blouin, E.F.; Manzano-Roman, R.; Naranjo, V.; Almazan, C.; Perez de la Lastra, J.M.; Zivkovic, Z.; Jongejan, F.; Kocan, K.M. Functional genomic studies of tick cells in response to infection with the cattle pathogen, Anaplasma marginale. Genomics 2007, 90, 712722.

143. Rachinsky, A.; Guerrero, F.D.; Scoles, G.A. Differential protein expression in ovaries of uninfected and Babesia-infected southern cattle ticks, Rhipicephalus (Boophilus) microplus. Insect Biochem. Mol. Biol. 2007, 37, 1291-1308.

144. Sukumaran, B.; Narasimhan, S.; Anderson, J.F.; DePonte, K.; Marcantonio, N.; Krishnan, M.N.; Fish, D.; Telford, S.R.; Kantor, F.S.; Fikrig, E. An Ixodes scapularis protein required for survival of Anaplasma phagocytophilum in tick salivary glands. J. Exp. Med. 2006, 203, 1507-1517.

145. Heekin, A.M.; Guerrero, F.D.; Bendele, K.G.; Saldivar, L.; Scoles, G.A.; Gondro, C.; Nene, V.; Djikeng, A.; Brayton, K.A. Analysis of Babesia bovis infection-induced gene expression changes in larvae from the cattle tick, Rhipicephalus (Boophilus) microplus. Parasit Vectors 2012, 5, 162.

146. Das, S.; Banerjee, G.; DePonte, K.; Marcantonio, N.; Kantor, F.S.; Fikrig, E. Salp25D, an Ixodes scapularis antioxidant, is 1 of 14 immunodominant antigens in engorged tick salivary glands. $J$. Infect. Dis 2001, 184, 1056-1064.

147. Ramamoorthi, N.; Narasimhan, S.; Pal, U.; Bao, F.; Yang, X.F.; Fish, D.; Anguita, J.; Norgard, M.V.; Kantor, F.S.; Anderson, J.F.; et al. The Lyme disease agent exploits a tick protein to infect the mammalian host. Nature 2005, 436, 573-577.

148. Hynes, W.L.; Stokes, M.M.; Hensley, S.M.; Todd, S.M.; Sonenshine, D.E. Using RNA interference to determine the role of varisin in the innate immune system of the hard tick Dermacentor variabilis (Acari: Ixodidae). Exp. Appl. Acarol. 2008, 46, 7-15.

149. Antunes, S.; Galindo, R.C.; Almazan, C.; Rudenko, N.; Golovchenko, M.; Grubhoffer, L.; Shkap, V.; do Rosario, V.; de la Fuente, J.; Domingos, A. Functional genomics studies of Rhipicephalus (Boophilus) annulatus ticks in response to infection with the cattle protozoan parasite, Babesia bigemina. Int J. Parasitol. 2012, 42, 187-195.

150. Pittendrigh, B.R.; Berenbaum, M.R.; Seufferheld, M.J.; Margam, V.M.; Strycharz, J.P.; Yoon, K.S.; Sun, W.; Reenan, R.; Lee, S.H.; Clark, J.M. Simplify, simplify: Lifestyle and compact genome of the body louse provide a unique functional genomics opportunity. Commun. Integr. Biol. 2011, 4, 188-191.

151. Kirkness, E.F.; Haas, B.J.; Sun, W.; Braig, H.R.; Perotti, M.A.; Clark, J.M.; Lee, S.H.; Robertson, H.M.; Kennedy, R.C.; Elhaik, E.; et al. Genome sequences of the human body louse and its primary endosymbiont provide insights into the permanent parasitic lifestyle. Proc. Natl. Acad. Sci. USA 2010, 107, 12168-12173.

152. Yoon, K.S.; Strycharz, J.P.; Baek, J.H.; Sun, W.; Kim, J.H.; Kang, J.S.; Pittendrigh, B.R.; Lee, S.H.; Clark, J.M. Brief exposures of human body lice to sublethal amounts of ivermectin overtranscribes detoxification genes involved in tolerance. Insect Mol. Biol. 2011, 20, 687-699. 
153. Attardo, G.M.; Hansen, I.A.; Raikhel, A.S. Nutritional regulation of vitellogenesis in mosquitoes: implications for anautogeny. Insect Biochem. Mol. Biol. 2005, 35, 661-675.

154. Scott, T.W.; Takken, W. Feeding strategies of anthropophilic mosquitoes result in increased risk of pathogen transmission. Trends Parasitol. 2012, 28, 114-121.

155. Manzano-Roman, R.; Oleaga, A.; Perez-Sanchez, R.; Siles-Lucas, M.; Rollinson, D.; Hay, S.I. Gene Silencing in Parasites: Current Status and Future Prospects. Adv. Parasitol. 2012, 78, 1-55.

156. Belles, X. Beyond Drosophila: RNAi in vivo and functional genomics in insects. Annu. Rev. Entomol. 2010, 55, 111-128.

157. Zhang, X.; Zhang, J.; Zhu, K.Y. Chitosan/double-stranded RNA nanoparticle-mediated RNA interference to silence chitin synthase genes through larval feeding in the African malaria mosquito (Anopheles gambiae). Insect Mol. Biol. 2010, 19, 683-693.

158. Pridgeon, J.W.; Zhao, L.; Becnel, J.J.; Strickman, D.A.; Clark, G.G.; Linthicum, K.J. Topically applied AaeIAP1 double-stranded RNA kills female adults of Aedes aegypti. J. Med. Entomol. 2008, 45, 414-420.

159. Coy, M.R.; Sanscrainte, N.D.; Chalaire, K.C.; Inberg, A.; Maayan, I.; Glick, E.; Paldi, N.; Becnel, J.J. Gene silencing in adult Aedes aegypti mosquitoes through oral delivery of double-stranded RNA. J. Appl. Entomol. 2012, doi: 10.1111/j.1439-0418.2012.01713.x.

160. Gu, J.; Liu, M.; Deng, Y.; Peng, H.; Chen, X. Development of an efficient recombinant mosquito densovirus-mediated RNA interference system and its preliminary application in mosquito control. PLoS One 2011, 6, e21329.

161. Boisson, B.; Jacques, J.C.; Choumet, V.; Martin, E.; Xu, J.; Vernick, K.; Bourgouin, C. Gene silencing in mosquito salivary glands by RNAi. FEBS Lett. 2006, 580, 1988-1992.

162. Vodovar, N.; Saleh, M.-C. Of Insects and Viruses: The Role of Small RNAs in Insect Defence. Adv. Insect Physiol. 2012, 42, 1-36.

163. Gulia-Nuss, M.; Robertson, A.E.; Brown, M.R.; Strand, M.R. Insulin-like peptides and the target of rapamycin pathway coordinately regulate blood digestion and egg maturation in the mosquito Aedes aegypti. PLoS One 2011, 6, e20401.

164. Hansen, I.A.; Attardo, G.M.; Roy, S.G.; Raikhel, A.S. Target of rapamycin-dependent activation of S6 kinase is a central step in the transduction of nutritional signals during egg development in a mosquito. J. Biol Chem 2005, 280, 20565-20572.

165. Hansen, I.A.; Boudko, D.Y.; Shiao, S.H.; Voronov, D.A.; Meleshkevitch, E.A.; Drake, L.L.; Aguirre, S.E.; Fox, J.M.; Attardo, G.M.; Raikhel, A.S. AaCAT1 of the yellow fever mosquito, Aedes aegypti: a novel histidine-specific amino acid transporter from the SLC7 family. J. Biol. Chem. 2011, 286, 10803-10813.

166. Roy, S.G.; Raikhel, A.S. The small GTPase Rheb is a key component linking amino acid signaling and TOR in the nutritional pathway that controls mosquito egg development. Insect Biochem. Mol. Biol. 2011, 41, 62-69.

167. Roy, S.G.; Raikhel, A.S. Nutritional and hormonal regulation of the TOR effector 4E-binding protein (4E-BP) in the mosquito Aedes aegypti. FASEB J. 2012, 26, 1334-1342.

168. Alabaster, A.; Isoe, J.; Zhou, G.; Lee, A.; Murphy, A.; Day, W.A.; Miesfeld, R.L. Deficiencies in acetyl-CoA carboxylase and fatty acid synthase 1 differentially affect eggshell formation and blood meal digestion in Aedes aegypti. Insect Biochem. Mol. Biol. 2011, 41, 946-955. 
169. Isoe, J.; Collins, J.; Badgandi, H.; Day, W.A.; Miesfeld, R.L. Defects in coatomer protein I (COPI) transport cause blood feeding-induced mortality in Yellow Fever mosquitoes. Proc. Natl. Acad. Sci. USA 2011, 108, E211-E217.

170. Roy, S.G.; Hansen, I.A.; Raikhel, A.S. Effect of insulin and 20-hydroxyecdysone in the fat body of the yellow fever mosquito, Aedes aegypti. Insect Biochem. Mol. Biol. 2007, 37, 1317-1326.

171. Hansen, I.A.; Attardo, G.M.; Park, J.H.; Peng, Q.; Raikhel, A.S. Target of rapamycin-mediated amino acid signaling in mosquito anautogeny. Proc. Natl. Acad. Sci. USA 2004, 101, 10626-10631.

172. Biessmann, H.; Andronopoulou, E.; Biessmann, M.R.; Douris, V.; Dimitratos, S.D.; Eliopoulos, E.; Guerin, P.M.; Iatrou, K.; Justice, R.W.; Krober, T.; et al. The Anopheles gambiae odorant binding protein 1 (AgamOBP1) mediates indole recognition in the antennae of female mosquitoes. PLoS One 2010, 5, e9471.

173. Pelletier, J.; Guidolin, A.; Syed, Z.; Cornel, A.J.; Leal, W.S. Knockdown of a Mosquito Odorantbinding Protein Involved in the Sensitive Detection of Oviposition Attractants. J. Chem. Ecol. 2010, 36.

174. Erdelyan, C.N.; Mahood, T.H.; Bader, T.S.; Whyard, S. Functional validation of the carbon dioxide receptor genes in Aedes aegypti mosquitoes using RNA interference. Insect Mol. Biol. 2012, 21, 119-127.

175. Caplen, N.J.; Zheng, Z.; Falgout, B.; Morgan, R.A. Inhibition of viral gene expression and replication in mosquito cells by dsRNA-triggered RNA interference. Mol. Ther 2002, 6, 243-251.

176. Adelman, Z.N.; Sanchez-Vargas, I.; Travanty, E.A.; Carlson, J.O.; Beaty, B.J.; Blair, C.D.; Olson, K.E. RNA silencing of dengue virus type 2 replication in transformed C6/36 mosquito cells transcribing an inverted-repeat RNA derived from the virus genome. J. Virol. 2002, 76, 12925-12933.

177. Blandin, S.; Moita, L.F.; Kocher, T.; Wilm, M.; Kafatos, F.C.; Levashina, E.A. Reverse genetics in the mosquito Anopheles gambiae: targeted disruption of the Defensin gene. EMBO Rep. 2002, 3, 852-856.

178. Brown, A.E.; Bugeon, L.; Crisanti, A.; Catteruccia, F. Stable and heritable gene silencing in the malaria vector Anopheles stephensi. Nucleic Acids. Res. 2003, 31, e85.

179. Franz, A.W.; Sanchez-Vargas, I.; Adelman, Z.N.; Blair, C.D.; Beaty, B.J.; James, A.A.; Olson, K.E. Engineering RNA interference-based resistance to dengue virus type 2 in genetically modified Aedes aegypti. Proc. Natl. Acad. Sci. USA 2006, 103, 4198-4203.

180. Keene, K.M.; Foy, B.D.; Sanchez-Vargas, I.; Beaty, B.J.; Blair, C.D.; Olson, K.E. RNA interference acts as a natural antiviral response to O'nyong-nyong virus (Alphavirus; Togaviridae) infection of Anopheles gambiae. Proc. Natl. Acad. Sci. USA 2004, 101, 17240-17245.

181. Blair, C.D. Mosquito RNAi is the major innate immune pathway controlling arbovirus infection and transmission. Future Microbiol. 2011, 6, 265-277.

182. Attarzadeh-Yazdi, G.; Fragkoudis, R.; Chi, Y.; Siu, R.W.; Ulper, L.; Barry, G.; RodriguezAndres, J.; Nash, A.A.; Bouloy, M.; Merits, A.; et al. Cell-to-cell spread of the RNA interference 
response suppresses Semliki Forest virus (SFV) infection of mosquito cell cultures and cannot be antagonized by SFV. J. Virol. 2009, 83, 5735-5748.

183. Vodovar, N.; Bronkhorst, A.W.; van Cleef, K.W.; Miesen, P.; Blanc, H.; van Rij, R.P.; Saleh, M.C. Arbovirus-derived piRNAs exhibit a ping-pong signature in mosquito cells. PLoS One 2012, 7, e30861.

184. Franz, A.W.; Sanchez-Vargas, I.; Piper, J.; Smith, M.R.; Khoo, C.C.; James, A.A.; Olson, K.E. Stability and loss of a virus resistance phenotype over time in transgenic mosquitoes harbouring an antiviral effector gene. Insect Mol. Biol. 2009, 18, 661-672.

185. Xi, Z.; Ramirez, J.L.; Dimopoulos, G. The Aedes aegypti toll pathway controls dengue virus infection. PLoS Pathog. 2008, 4, e1000098.

186. Souza-Neto, J.A.; Sim, S.; Dimopoulos, G. An evolutionary conserved function of the JAKSTAT pathway in anti-dengue defense. Proc. Natl. Acad. Sci. USA 2009, 106, 17841-17846.

187. Fragkoudis, R.; Attarzadeh-Yazdi, G.; Nash, A.A.; Fazakerley, J.K.; Kohl, A. Advances in dissecting mosquito innate immune responses to arbovirus infection. J. Gen. Virol. 2009, 90, 2061-2072.

188. Merkling, S.H.; van Rij, R.P. Beyond RNAi: Antiviral defense strategies in Drosophila and Mosquito. J. Insect Physiol. 2012, Jul 20, 22824741.

189. Sim, S.; Dimopoulos, G. Dengue virus inhibits immune responses in Aedes aegypti cells. PLoS One 2010, 5, e10678.

190. Colpitts, T.M.; Cox, J.; Vanlandingham, D.L.; Feitosa, F.M.; Cheng, G.; Kurscheid, S.; Wang, P.; Krishnan, M.N.; Higgs, S.; Fikrig, E. Alterations in the Aedes aegypti transcriptome during infection with West Nile, dengue and yellow fever viruses. PLoS Pathog. 2011, 7, e1002189.

191. Benedict, C.A.; Norris, P.S.; Ware, C.F. To kill or be killed: viral evasion of apoptosis. Nat. Immunol. 2002, 3, 1013-1018.

192. Chen, T.H.; Tang, P.; Yang, C.F.; Kao, L.H.; Lo, Y.P.; Chuang, C.K.; Shih, Y.T.; Chen, W.J. Antioxidant defense is one of the mechanisms by which mosquito cells survive dengue 2 viral infection. Virology 2011, 410, 410-417.

193. Chen, T.H.; Lo, Y.P.; Yang, C.F.; Chen, W.J. Additive protection by antioxidant and apoptosis-inhibiting effects on mosquito cells with dengue 2 virus infection. PLoS Negl. Trop. Dis. 2012, 6, e1613.

194. Cirimotich, C.M.; Dong, Y.; Garver, L.S.; Sim, S.; Dimopoulos, G. Mosquito immune defenses against Plasmodium infection. Dev. Comp. Immunol. 2010, 34, 387-395.

195. Blandin, S.A.; Levashina, E.A. Reverse genetics analysis of antiparasitic responses in the malaria vector, Anopheles gambiae. Meth. Mol. Biol. 2008, 415, 365-377.

196. Marois, E. The multifaceted mosquito anti-Plasmodium response. Curr. Opin. Microbiol. 2011, 14, 429-435.

197. Blandin, S.; Shiao, S.H.; Moita, L.F.; Janse, C.J.; Waters, A.P.; Kafatos, F.C.; Levashina, E.A. Complement-like protein TEP1 is a determinant of vectorial capacity in the malaria vector Anopheles gambiae. Cell 2004, 116, 661-670.

198. Osta, M.A.; Christophides, G.K.; Kafatos, F.C. Effects of mosquito genes on Plasmodium development. Science 2004, 303, 2030-2032. 
199. Riehle, M.M.; Markianos, K.; Niare, O.; Xu, J.; Li, J.; Toure, A.M.; Podiougou, B.; Oduol, F.; Diawara, S.; Diallo, M.; et al. Natural malaria infection in Anopheles gambiae is regulated by a single genomic control region. Science 2006, 312, 577-579.

200. Povelones, M.; Waterhouse, R.M.; Kafatos, F.C.; Christophides, G.K. Leucine-rich repeat protein complex activates mosquito complement in defense against Plasmodium parasites. Science 2009, 324, 258-261.

201. Fraiture, M.; Baxter, R.H.; Steinert, S.; Chelliah, Y.; Frolet, C.; Quispe-Tintaya, W.; Hoffmann, J.A.; Blandin, S.A.; Levashina, E.A. Two mosquito LRR proteins function as complement control factors in the TEP1-mediated killing of Plasmodium. Cell. Host Microbe 2009, 5, 273-284.

202. Ghosh, A.K.; Devenport, M.; Jethwaney, D.; Kalume, D.E.; Pandey, A.; Anderson, V.E.; Sultan, A.A.; Kumar, N.; Jacobs-Lorena, M. Malaria parasite invasion of the mosquito salivary gland requires interaction between the Plasmodium TRAP and the Anopheles saglin proteins. PLoS Pathog. 2009, 5, e1000265.

203. Dong, Y.; Taylor, H.E.; Dimopoulos, G. AgDscam, a hypervariable immunoglobulin domaincontaining receptor of the Anopheles gambiae innate immune system. PLoS Biol. 2006, 4, e229.

204. Dong, Y.; Dimopoulos, G. Anopheles fibrinogen-related proteins provide expanded pattern recognition capacity against bacteria and malaria parasites. J. Biol. Chem. 2009, 284, 9835-9844.

205. Shin, S.W.; Zou, Z.; Raikhel, A.S. A new factor in the Aedes aegypti immune response: CLSP2 modulates melanization. EMBO Rep. 2011, 12, 938-943.

206. Rodrigues, J.; Oliveira, G.A.; Kotsyfakis, M.; Dixit, R.; Molina-Cruz, A.; Jochim, R.; BarillasMury, C. An epithelial serine protease, AgESP, is required for Plasmodium invasion in the mosquito Anopheles gambiae. PLoS One 2012, 7, e35210.

207. Chertemps, T.; Mitri, C.; Perrot, S.; Sautereau, J.; Jacques, J.C.; Thiery, I.; Bourgouin, C.; Rosinski-Chupin, I. Anopheles gambiae PRS1 modulates Plasmodium development at both midgut and salivary gland steps. PLoS One 2010, 5, e11538.

208. Kajla, M.K.; Shi, L.; Li, B.; Luckhart, S.; Li, J.; Paskewitz, S.M. A new role for an old antimicrobial: lysozyme c-1 can function to protect malaria parasites in Anopheles mosquitoes. PLoS One 2011, 6, e19649.

209. Mendes, A.M.; Schlegelmilch, T.; Cohuet, A.; Awono-Ambene, P.; De Iorio, M.; Fontenille, D.; Morlais, I.; Christophides, G.K.; Kafatos, F.C.; Vlachou, D. Conserved mosquito/parasite interactions affect development of Plasmodium falciparum in Africa. PLoS Pathog. 2008, 4, e1000069.

210. Lavore, A.; Pagola, L.; Esponda-Behrens, N.; Rivera-Pomar, R. The gap gene giant of Rhodnius prolixus is maternally expressed and required for proper head and abdomen formation. Dev. Biol. 2012, 361, 147-155.

211. Araujo, R.N.; Campos, I.T.; Tanaka, A.S.; Santos, A.; Gontijo, N.F.; Lehane, M.J.; Pereira, M.H. Brasiliensin: A novel intestinal thrombin inhibitor from Triatoma brasiliensis (Hemiptera: Reduviidae) with an important role in blood intake. Int. J. Parasitol. 2007, 37, 1351-1358.

212. Lye, L.F.; Owens, K.; Shi, H.; Murta, S.M.; Vieira, A.C.; Turco, S.J.; Tschudi, C.; Ullu, E.; Beverley, S.M. Retention and loss of RNA interference pathways in trypanosomatid protozoans. PLoS Pathog. 2010, 6, e1001161. 
213. Franzen, O.; Arner, E.; Ferella, M.; Nilsson, D.; Respuela, P.; Carninci, P.; Hayashizaki, Y.; Aslund, L.; Andersson, B.; Daub, C.O. The short non-coding transcriptome of the protozoan parasite Trypanosoma cruzi. PLoS Negl. Trop. Dis. 2011, 5, e1283.

214. Genovesio, A.; Giardini, M.A.; Kwon, Y.J.; de Macedo Dossin, F.; Choi, S.Y.; Kim, N.Y.; Kim, H.C.; Jung, S.Y.; Schenkman, S.; Almeida, I.C.; et al. Visual genome-wide RNAi screening to identify human host factors required for Trypanosoma cruzi infection. PLoS One 2011, 6, e19733.

215. Taylor, M.C.; Huang, H.; Kelly, J.M. Genetic techniques in Trypanosoma cruzi. Adv. Parasitol. 2011, 75, 231-250.

216. Manzano-Roman, R.; Oleaga, A.; Perez-Sanchez, R.; Siles-Lucas, M. Gene silencing in parasites: current status and future prospects. Adv. Parasitol. 2012, 78, 1-55.

217. Yang, G.; Attardo, G.M.; Lohs, C.; Aksoy, S. Molecular characterization of two novel milk proteins in the tsetse fly (Glossina morsitans morsitans). Insect Mol. Biol. 2010, 19, 253-262.

218. Lehane, M.J.; Gibson, W.; Lehane, S.M. Differential expression of fat body genes in Glossina morsitans morsitans following infection with Trypanosoma brucei brucei. Int. J. Parasitol. 2008, 38, 93-101.

219. Subota, I.; Rotureau, B.; Blisnick, T.; Ngwabyt, S.; Durand-Dubief, M.; Engstler, M.; Bastin, P. ALBA proteins are stage regulated during trypanosome development in the tsetse fly and participate in differentiation. Mol. Biol. Cell 2011, 22, 4205-4219.

220. Haines, L.R.; Lehane, S.M.; Pearson, T.W.; Lehane, M.J. Tsetse EP protein protects the fly midgut from trypanosome establishment. PLoS Pathog. 2010, 6, e1000793.

221. Natesan, S.K.; Peacock, L.; Leung, K.F.; Matthews, K.R.; Gibson, W.; Field, M.C. The trypanosome Rab-related proteins RabX1 and RabX2 play no role in intracellular trafficking but may be involved in fly infectivity. PLoS One 2009, 4, e7217.

222. Wang, J.; Wu, Y.; Yang, G.; Aksoy, S. Interactions between mutualist Wigglesworthia and tsetse peptidoglycan recognition protein (PGRP-LB) influence trypanosome transmission. Proc. Natl. Acad. Sci. USA 2009, 106, 12133-12138.

223. Caljon, G.; Broos, K.; De Goeyse, I.; De Ridder, K.; Sternberg, J.M.; Coosemans, M.; De Baetselier, P.; Guisez, Y.; Den Abbeele, J.V. Identification of a functional Antigen5-related allergen in the saliva of a blood feeding insect, the tsetse fly. Insect Biochem. Mol. Biol. 2009, 39, 332-341.

224. Smith, T.K.; Butikofer, P. Lipid metabolism in Trypanosoma brucei. Mol. Biochem. Parasitol. 2010, 172, 66-79.

225. Balana-Fouce, R.; Reguera, R.M. RNA interference in Trypanosoma brucei: a high-throughput engine for functional genomics in trypanosomatids? Trends Parasitol. 2007, 23, 348-351.

226. Hammarton, T.C. Cell cycle regulation in Trypanosoma brucei. Mol. Biochem. Parasitol. 2007, 153, 1-8.

227. Coutinho-Abreu, I.V.; Zhu, K.Y.; Ramalho-Ortigao, M. Transgenesis and paratransgenesis to control insect-borne diseases: current status and future challenges. Parasitol. Int. 2010, 59, 1-8.

228. Malcolm, J.; Fraser, J. Insect trangenesis: Current applications and future prospects. Annu. Rev. Entomol. 2012, 57, 267-289. 
229. Terenius, O.; Marinotti, O.; Sieglaff, D.; James, A.A. Molecular genetic manipulation of vector mosquitoes. Cell Host Microbe 2008, 4, 417-423.

230. Shin, S.W.; Kokoza, V.A.; Raikhel, A.S. Transgenesis and reverse genetics of mosquito innate immunity. J. Exp. Biol. 2003, 206, 3835-3843.

231. Magalhaes, T.; Leandro, D.C.; Ayres, C.F. Knock-down of REL2, but not defensin A, augments Aedes aegypti susceptibility to Bacillus subtilis and Escherichia coli. Acta Trop. 2010, 113, 167-173.

232. Garver, L.S.; Bahia, A.C.; Das, S.; Souza-Neto, J.A.; Shiao, J.; Dong, Y.; Dimopoulos, G. Anopheles Imd pathway factors and effectors in infection intensity-dependent anti-Plasmodium action. PLoS Pathog. 2012, 8, e1002737.

233. Antonova, Y.; Alvarez, K.S.; Kim, Y.J.; Kokoza, V.; Raikhel, A.S. The role of NF-kappaB factor REL2 in the Aedes aegypti immune response. Insect Biochem. Mol. Biol. 2009, 39, 303-314.

234. Bian, G.; Shin, S.W.; Cheon, H.M.; Kokoza, V.; Raikhel, A.S. Transgenic alteration of Toll immune pathway in the female mosquito Aedes aegypti. Proc. Natl. Acad. Sci. USA 2005, 102, 13568-13573.

235. Erickson, S.M.; Xi, Z.; Mayhew, G.F.; Ramirez, J.L.; Aliota, M.T.; Christensen, B.M.; Dimopoulos, G. Mosquito infection responses to developing filarial worms. PLoS Negl. Trop. Dis. 2009, 3, e529.

236. Meister, S.; Kanzok, S.M.; Zheng, X.L.; Luna, C.; Li, T.R.; Hoa, N.T.; Clayton, J.R.; White, K.P.; Kafatos, F.C.; Christophides, G.K.; et al. Immune signaling pathways regulating bacterial and malaria parasite infection of the mosquito Anopheles gambiae. Proc. Natl. Acad. Sci. USA 2005 2005, 102, 11420-11425.

237. Dinglasan, R.R.; Kalume, D.E.; Kanzok, S.M.; Ghosh, A.K.; Muratova, O.; Pandey, A.; JacobsLorena, M. Disruption of Plasmodium falciparum development by antibodies against a conserved mosquito midgut antigen. Proc. Natl. Acad. Sci. USA 2007, 104, 13461-13466.

238. Mathur, G.; Sanchez-Vargas, I.; Alvarez, D.; Olson, K.E.; Marinotti, O.; James, A.A. Transgenemediated suppression of dengue viruses in the salivary glands of the yellow fever mosquito, Aedes aegypti. Insect Mol. Biol. 2010, 19, 753-763.

239. Hurwitz, I.; Fieck, A.; Read, A.; Hillesland, H.; Klein, N.; Kang, A.; Durvasula, R. Paratransgenic control of vector borne diseases. Int. J. Biol. Sci. 2011, 7, 1334-1344.

240. Cheng, Q.; Aksoy, S. Tissue tropism, transmission and expression of foreign genes in vivo in midgut symbionts of tetse flies. Insect Mol. Biol 1999, 8, 125-132.

241. Favia, G.; Ricci, I.; Damiani, C.; Raddadi, N.; Crotti, E.; Marzorati, M.; Rizzi, A.; Urso, R.; Brusetti, L.; Borin, S.; et al. Bacteria of the genus Asaia stably associate with Anopheles stephensi, an Asian malarial mosquito vector. Proc. Natl. Acad. Sci. USA 2007, 22, 9047-9051.

242. Damiani, C.; Ricci, I.; Crotti, E.; Rossi, P.; Rizzi, A.; Scuppa, P.; Esposito, F.; Bandi, C.; Daffonchio, D.; Favia, G. Paternal transmission of symbiotic bacteria in malaria vectors. Curr. Biol. 2008, 18, R1087-1088.

243. Ren, X.; Hoiczyk, E.; Rasgon, J.L. Viral paratransgenesis in the malaria vector Anopheles gambiae. PLoS Pathog. 2008, 4, e1000135. 
244. Ward, T.W.; Jenkins, M.S.; Afanasiev, B.N.; Edwards, M.; Duda, B.A.; Suchman, E.; JacobsLorena, M.; Beaty, B.J.; Carlson, J.O. Aedes aegypti transducing densovirus pathogenesis and expression in Aedes aegypti and Anopheles gambiae larvae. Insect Mol. Biol. 2002, 10, 397-405.

245. Hong-Geller, E.; Micheva-Viteva, S.N. Functional gene discovery using RNA interference-based genomic screens to combat pathogen infection. Curr. Drug Discov. Technol. 2010, 7, 86-94.

246. Drinnenberg, I.A.; Weinberg, D.E.; Xie, K.T.; Mower, J.P.; Wolfe, K.H.; Fink, G.R.; Bartel, D.P. RNAi in budding yeast. Science 2009, 326, 544-550.

(C) 2012 by the authors; licensee MDPI, Basel, Switzerland. This article is an open access article distributed under the terms and conditions of the Creative Commons Attribution license (http://creativecommons.org/licenses/by/3.0/). 